LA-UR- $97-3179$

Title:

\title{
COMPARISON OF CALCULATIONS OF FRAGMENT PRODUCTION RATES
}

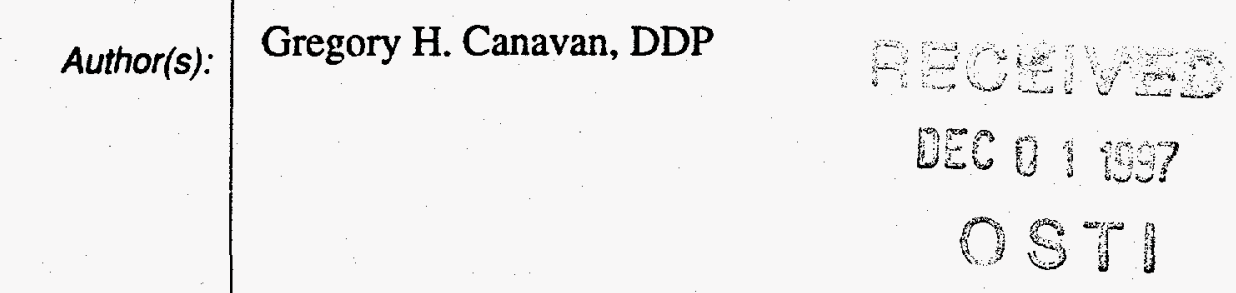

Submitted to:

For discussions outside the Laboratory

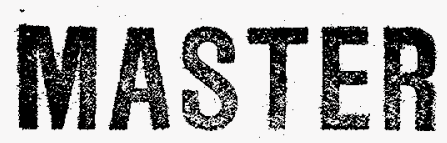

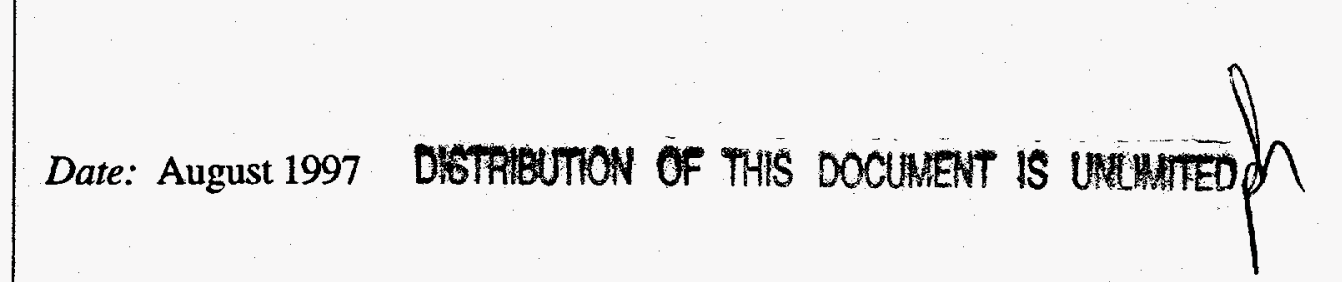

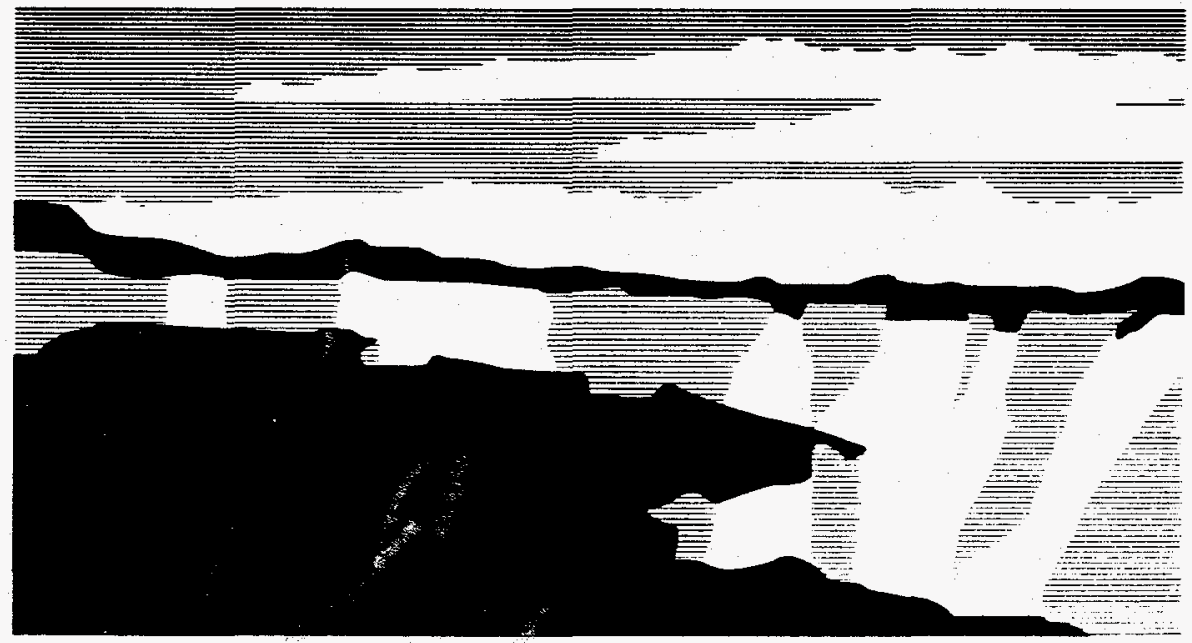

Los Alamos National Laboratory, an affirmative action/equal opportunity employer, is operated by the University of Calitornia for the U.S. Department of Energy under contract W-7405-ENG-36. By acceptance of this article, the publisher recognizes that the U.S. Government retains a nonexclusive, royalty-free license to publish or reproduce the published form of this contribution, or to aliow others to do so, for U.S. Government purposes. The Los Alamos National Laboratory requests that the publisher identify this article as work performed under the auspices of the U.S. Department of Energy. 


\section{DISCLAMIXR}

Portions of this docament ming be illegible in electronic inege products. Imoges are produced from the best available original docementer 


\section{DISCLAIMER}

This report was prepared as an account of work sponsored by an agency of the United States Government. Neither the United States Government nor any agency thereof, nor any of their employees, makes any warranty, express or implied, or assumes any legal liability or responsibility for the accuracy, completeness, or usefulness of any information, apparatus, product, or process disclosed, or represents that its use would not infringe privately owned rights. Reference herein to any specific commercial product, process, or service by trade name, trademark, manufacturer, or otherwise does not necessarily constitute or imply its endorsement, recommendation, or favoring by the United States Government or any agency thereof. The views and opinions of authors expressed herein do not necessarily state or reflect those of the United States Government or any agency thereof. 


\title{
COMPARISON OF CALCULATIONS OF FRAGMENT PRODUCTION RATES
}

\author{
Gregory H. Canavan
}

\begin{abstract}
Differences between NASA and DoD estimates of fragment production rates in space debris collisions are shown to be due primarily to different choices of the exponent in the debris distribution. The sensitivity to this parameter over the range of values consistent with experimental data is discussed.
\end{abstract}

This note compares NASA and DoD estimates of fragment production rates in space debris collisions. The calculations are performed for a consistent set of debris distribution functions, which are implicit in the set of integrated collision frequencies provided by NASA Johnson Space Center (JSC) in Attachment $\mathrm{A}^{1}$ for comparison with calculations in the report by the USAF Scientific Advisory Board (SAB). ${ }^{2}$ Attachment A gives a useful table of collision frequencies, defines NASA's equation for fragment production, and provides references that are used as the basis for the comparisons. This information makes it possible to understand and achieve agreement with JSC's average masses for all collisions and to discuss the discrepancies in the fragment production rate estimates based on them. The agreement on the average mass involved in all collisions is on the order of $1 \%$; the agreement on average masses in catastrophic collisions is on the order of $6 \%$, which is within the uncertainties in averaging proceedures, once it is recognized that only about $52 \%$ of the collisions in the JSC table are catastrophic.

Empirical fragment distribution kernels are reviewed and proper metheds for averaging them over debris and collision frequency distributions are derived, leading to a prediction of 102 fragments per collision for the highly cascaded distributions presented. While the substitution of average masses into fragmentaion kernels for the estimation of fragment production rates is technically incorrect, the agreement with the corrected JSC fragment production rates is within a factor of two and readily traceable to the different parameters used in the two calculations. For JSC's collision frequencies, the JSC production rate overestimates that from the SAB study by about $90 \%$ due to the choice of the parameter used in the fragmentation kernel. The SAB results are also compared to the predictions of the FASTT model developed by DNA to model the DoD impact experiments, which predicts a lower number of fragments per collison than that calculated by the SAB for the average parameters from the DNA test series.

This comparison was stimulated by the apparent contradiction between JSC and SAB estimates of the average number of fragments per collison. The differences between the two are shown to result primarily from improper normalization, confusion between catastrophic and total collisions, and the use of a parameter in describing the fragment distribution that is not supported by the empirical DoD data base on hypervelocity collisions. The sensitivity to this parameter due 
to the range of values consistent with experimental data is discussed. The remaining discrepancy is within the errors expected for the spuriously cascaded distributions used for comparison.

JSC debris collision rate estimates are given in Table 1 of Appendix A. These estimates of cumulative collision rates are derived from 10 Monte-Carlo simulations of debris growth over the next century from current conditions for the same launch rate synthesized by repeating that of 1985-1995 in each decade for every simulation. The growth of cumulative collisions in each case is shown in Fig. 1 of Attachment A, which indicates variances on the order of 10-20\%, as is appropriate for the small number of cases. These numbers are sufficiently well behaved to make the average quantities computed below meaningful, if a bit noisy.

Table 1 gives the collision frequency between objects of various sizes, averaged over bins with ratios of upper to lower masses of about a factor of 2.8. Summing the entries gives an average of 58.4 collisions in 100 years or 0.58 collisions/yr. That is a factor of $\approx 0.58 / 0.05 \approx$ 11.6-fold greater than the present rate, but JSC indicates ${ }^{3}$ that the increase due to cascading can be normalized to first order by dividing each element in the matrix by a factor of 11.6. Table I is used as is below and the results are so normalized where necessary.

Figure 1 shows the average number of collisions of all types per century from Table 1 of Attachment $A$ as a function of the diameters of the projectile and target fragments, where the projectile is defined as the colliding partner with the smaller diameter $D_{p}$ and mass $M_{p}$ and the target as the partner with the larger diameter $\mathrm{D}_{\mathrm{t}}$ and mass $\mathrm{M}_{\mathrm{t}}$, which prevents double counting of collisions. This average collision frequency is denoted by $F\left(D_{p}, D_{t}\right)$. The fragment sizes defined in Table 1 of Attachment $A$ range from a bin from 0.1 to $0.16 \mathrm{~m}$, which contains the smallest fragments, to a bin from 6.3 to $10 \mathrm{~m}$, which contains the largest. The coordinates are oriented so that the origin $(0.16,0.16)$ is at the lower left and the largest fragments $(10,10)$ are at the right.

The value at the origin of about 0.2 collisions/century for fragments from 0.1 to $0.16 \mathrm{~m}$ corresponds to the top entry of Table 1 of Attachment A. There is a detectable number of collisions of these fragments despite their small size because of their large number. ${ }^{4}$ For $D_{p}=$ $0.16 \mathrm{~m}$, as $D_{t}$ increases there are a few local maxima, a sharp increase at $D_{t}=1.6$, and a pronounced peak at $D_{t}=6.3 \mathrm{~m}$, after which the number falls, indicating that that the most numerous collisions are between the numerous small particles and the few large ones.

As $D_{p}$ increases, similar scaling on $D_{t}$ is seen, but the prominence of the peaks at large $D_{t}$ falls due to the reduction in the number of target particles in the distribution. However, there are secondary peaks at 2.5 and $6.3 \mathrm{~m}$, where the large size of the target particles overcomes their lower numbers to produce peaks about $15 \%$ as large as that at $(0.16,0.63)$.

The bottom curve in Fig. 2 shows collisions summed over targets size, $\Sigma_{D t} F\left(D_{p}, D_{t}\right)$, as a function of projectile size. The value is about 16.8 collisions/century at $D_{p}=0.16 \mathrm{~m}$, due largely to the large peak at $F(0.16,6.3)$. The sum falls with increasing $D_{p}$ by about an order of 
magnitude by $1 \mathrm{~m}$, where it stabilizes at about 3 through $D_{p}=6 \mathrm{~m}$, after which it falls by another order of magnitude for the largest $10 \mathrm{~m}$ bin, consistent with the interpretation of Fig. 1 that collisions primarily involve the large flux of small fragments on the few large targets. The top curve is the cumulative number of collisions, which is obtained by summing the lower curve up to the value of $D_{p}$ indicated, i.e., $\Sigma_{0} D_{p} \Sigma_{D t} F\left(D_{p}, D_{t}\right)$. At $D_{p}=0.16 m$ the cumulative is equal to the sum. It increases rapidly with $D_{p}$ up to about $1 \mathrm{~m}$; more slowly thereafter. It reaches about $50 \%$ of the total of $58.4 /$ century by $\mathrm{D}_{\mathrm{p}}=0.25 \mathrm{~m}$ and $80 \%$ by $2.5 \mathrm{~m}$, again reflecting the dominance of collisions of small projectiles with large targets in total collisions. Figure 3 shows the sum and cumulative collisions as a function of target size, $\Sigma 0^{D t} \sum_{D p} F\left(D_{p}, D_{t}\right)$, which increase roughly as $D_{t}{ }^{3 / 2}$, which again indicates a strong role for large fragments as targets for the numerous small fragments.

Catastrophic collisions. The dashed lines around the lower left bins in Table 1 of App. A identify collisions that are not catastrophic, i.e., do not satisfy the requirement that the mass of the projectile be within a factor of 1,000 of the mass of the target for complete fragmentation, 5 determined by JSC from inspection of the DoD-DNA impact experiment data base. 6 Smaller impactors cause only partial fragmentation of targets. ${ }^{7}$ Excluding these non-catastrophic collisions produces the catastropic collisions per century $G\left(D_{p}, D_{t}\right)$ distribution shown in Fig. 4, in which the peaks at small $D_{p}$ and large $D_{t}$ sen in Fig. 1 are suppressed by the elimination of the numerous collisions involving projectiles too small to cause catastrophic collisions.

Table 1 of Attachment A indicates that the $\leq 0.16 \mathrm{~m}$ objects have a maximum mass of $0.73 \mathrm{~kg}$, so they are too small by an order of magnitude to fragment the largest objects, which have masses up to $8589 \mathrm{~kg}$. Only fragments larger than $0.4 \mathrm{~m}$ can fragment them. By elminating collisions with target to projectile mass ratios over 1,000 , JSC reduces the collisions to those in the dashed region. That eliminates 27.8 collisions per century and reduces the number of catastrophic collisions per century to 30.6 - a reduction of about a factor of two.

Figure 4 shows that the net result is that the peak seen in Fig. 1 at $D_{p}=0.16 \mathrm{~m}$ is eliminated, and the peaks at 0.25 and $0.63 \mathrm{~m}$ are attenuated to about the levels of those at 2.5 and $6.3 \mathrm{~m}$, so that the secondary peaks such as the one at $(1.6,1.6)$ become more visible. Figure 5 shows the sum of $G$ over target size, $\Sigma D_{t} G\left(D_{p}, D_{t}\right)$, which indicates that contributions from all diameter bins are comparable. The cumulative $\sum_{0} \mathrm{Dp}_{\mathrm{p}} \sum_{\mathrm{Dt}} \mathrm{G}\left(\mathrm{D}_{\mathrm{p}}, \mathrm{D}_{\mathrm{t}}\right)$ rises rapidly to about $50 \%$ of the total of 30.6 by $D_{p}=1 \mathrm{~m}$, increases more slowly thereafter, and reaches about $80 \%$ of the total by $D_{p}=2.5 \mathrm{~m}$. Figure 6 shows that the sum and cumulative values as functions of $D_{t}$ resemble those in Fig. 1, although their slopes fall for larger targets.

The average mass per collision is evaluated by adding $D_{p}$ and $D_{t}$ for each element in $F\left(D_{p}, D_{t}\right)$, forming the product $\left(D_{p}+D_{t}\right) F\left(D_{p}, D_{t}\right)$ for each element in the collision matrix, summing over all $\mathrm{D}_{\mathrm{p}}$ and $\mathrm{D}_{\mathrm{t}}$, dividing the result by the total of 58.4 collisions per century, and 
multiplying by 0.6 , which produces the average mass involved per collision. The factor of 0.6 is needed because the JSC bins have a ratio of maximum to minimum mass of $\approx 2.8$, so the geometric average mass of each bin is only $\approx 1 / \sqrt{2} .8 \approx 0.6$ times the mass of the upper limit used to index the bin. This process is repeated with $F$ replaced by $G$ to determine the average mass per catastrophic collision.

Figure 7 shows the contributions to the average masses per collision sumed over $D_{t}$ as a functions of $D_{p}$. The upper curves are the sum and cumulative mass for all collisions. The contributions are a maximum at small $D_{p}$, fall until $D_{p}, \approx 1 \mathrm{~m}$, and then level out. The cumulative value rises rapidly, reaching more than half its asymptotic value of $2293 \mathrm{~kg}$ by $0.4 \mathrm{~m}$. The lower curves are the sum and cumulative mass for catastrophic collisions, which are minimized for the small $D_{p}$ fragments that cannot fragment the large objects. For $D_{p}$ larger than $1 \mathrm{~m}$, the distribution of contributions to the mass for catastrophic collisions approaches that for all collisions. and then level out at bout $100 \mathrm{~kg} / \mathrm{bin}$.

The top curve the cumulative contributions to average mass rises more slowly, reaching half its asymptotic value of $1102 \mathrm{~kg}$ by about $0.4 \mathrm{~m}$. Note that this value is the average total mass for the fragments involved in all collisions. Only a fraction $\approx 30.6 / 58.4 \approx 52.4 \%$ of the collisions in Table 1 are catastrophic, so the average mass of fragments involved in catastrophic collisions only is $1102 \mathrm{~kg} / 0.524=2103 \mathrm{~kg}$. These results are compared in Table I to those from the table of average geometric masses below the collision matrix on Table 1 of Attachment A.

\begin{tabular}{|c|c|c|c|}
\hline \multirow[t]{2}{*}{ Table I. } & \multicolumn{3}{|c|}{ Average Mass (kg) } \\
\hline & all collisions & catastrophic & difference $\%$ \\
\hline JSC & 2271 & 2007 & -12 \\
\hline SAB & 2293 & 2103 & -9 \\
\hline difference $\%$ & 1 & 5.8 & \\
\hline
\end{tabular}

The average masses compare well for both all and catastrophic collisions. The $1 \%$ in all collisions is in the noise and the $5.8 \%$ discrepancy could be acconted for by differences in averaging. Both calculations agree that the average mass falls by $9-12 \%$ for catastrophic collisions as compared to all collisions-largely due to the exclusion of the exclusion of the collisions by the smallest fragments with the large ones. The mass involved in collisions falls by about a factor of two, from 2293 to $1102 \mathrm{~kg}$, as shown above, but only about half of the collisions are catastrophic, so the ratio of the average mass in all to catastrophic collisions appears relatively stable.

The fragment production kernel for hypervelocity impacts has been studied in DoD and NASA experiments, ${ }^{8}$ and the few dozen well diagnosed tests have been summarized and 
interpreted. ${ }^{9}$ The results of those experiments can be fit reasonably well by expressions for the cumulative number of fragments with masses greater than $m$ of the form

$$
C=A\left(M_{t} / m\right)^{B} \text {, }
$$

where $\mathrm{M}_{\mathrm{t}}$ is the target mass, approximately the total fragment mass in those experiments, and $A$ and $B$ are parameters that characterize the number of framents produced. The value of $B$ can be inferred for each experiment from the slope of the plot of $\ln C$ versus $\ln \mathrm{m}$; $\mathrm{A}$ is determined by the intercept. The value of $B$ so determined is $0.62 \pm 0.07$. The $S A B$ report uses this average value of $B$ determines $A=1 / B-1$ from conservation of mass. 10

The average fragments per collision is determined by averaging Eq. (1) over the collision matrix of Table 1 of Apendix A to determine the average number of fragments produced per collision, which is 11

$$
\langle N\rangle=\Sigma^{\prime} Z\left(D_{p}, D_{t}, M_{f}\right) F\left(D_{p}, D_{t}\right) / \Sigma F\left(D_{p}, D_{t}\right),
$$

where $Z\left(D_{p}, D_{t}, M_{f}\right)$ is the average number of catalog particles of diameter greater than $0.1 \mathrm{~m}$ (or mass $\mathrm{M}_{\mathrm{f}} \geq 0 . .26 \mathrm{~kg}$, according to Table 1 of App. A) produced per collision between objects of mass $M_{p}$ and $M_{t} . F\left(D_{p}, D_{t}\right)$ is the collision rate between them, as represented in this comparison by the elements of the collision frequency matrix in Table 1 . The sum is over $D_{p}$ and $D_{t}$, and the prime indicates that the sum is to be taken only over catastrophic collisions, in which $F$ reduces to $G$, as non-catastrophic collisions do not produce additional particles. $Z$ is in general a function of $D_{p}, D_{t}, M_{f}$, and the ratio of projectile to target mass for catastrophic interaction. While $\mathrm{Z}$ is a function of mass, it is generally not a linear function of mass. Thus, it is not permissible to calculate the average mass per catastrophic collision

$$
\langle\mathrm{M}\rangle=\Sigma\left(\mathrm{M}_{\mathrm{p}}+\mathrm{M}_{\mathrm{t}}\right) \mathrm{G}\left(\mathrm{D}_{\mathrm{p}}, \mathrm{D}_{\mathrm{t}}\right) / \Sigma \mathrm{F}\left(\mathrm{D}_{\mathrm{p}}, \mathrm{D}_{\mathrm{t}}\right) \text {, }
$$

and use it in Eq. (1) to estimate the average number of fragments per collision, unless $\mathrm{Z}$ is linearly proportional to mass, $Z=K\left(D_{p}+D_{t}\right)$, in which case

$$
<N>\text { linear }=\sum K\left(M_{p}+M_{t}\right) G\left(D_{p}, D_{t}\right) / \sum F\left(D_{p}, D_{t}\right)=K<M>\text {. }
$$

For other dependences of $Z$ on $M_{p}$ and $M_{t}$, this approximation does not hold. In particular, for the form of $Z$ inferred from the DoD-DNA impact tests given by Eq. (1)

$$
\begin{aligned}
<\mathrm{N}>= & \Sigma^{\prime} \mathrm{A}\left[\left(\mathrm{M}_{\mathrm{p}}+\mathrm{M}_{\mathrm{t}}\right) / \mathrm{M}_{\mathrm{s}}\right]^{\mathrm{B}} \mathrm{F}\left(\mathrm{D}_{\mathrm{p}}, \mathrm{D}_{\mathrm{t}}\right) / \sum \mathrm{F}\left(\mathrm{D}_{\mathrm{p}}, \mathrm{D}_{\mathrm{t}}\right) \\
& \left.\neq \mathrm{A}\left\{\Sigma^{\prime}\left[\left(\mathrm{M}_{\mathrm{p}}+\mathrm{M}_{\mathrm{t}}\right) / \mathrm{M}_{\mathrm{s}}\right) \mathrm{F}\left(\mathrm{D}_{\mathrm{p}}, \mathrm{D}_{\mathrm{t}}\right)\right] / \sum \mathrm{F}\left(\mathrm{D}_{\mathrm{p}}, \mathrm{D}_{\mathrm{t}}\right)\right\}^{\mathrm{B}} .
\end{aligned}
$$

The errors in such an approximation can be quite large for the DoD-DNA $B \approx 0.62$ for which the scaling of $Z$ is far from linear, which strongly suppresses the effect of large excursions in mass relative to the linear approximation of Eq. (4). In any case, it is not necessary to use the approximation of linearity, as the full collision frequency matrix and kernel are available for this comprison, so the desired averages can easily be evaluated without approximation.

The average number of fragments per catastrophic collison is determined by averaging the fragmentation kernel of Eq. (1) over the catastrophic collison distribution $\mathrm{G}$ of 
Table 1. The kernel, under the optimistic assumption that all of the mass of both the projectile and target are converted into fragments is given by

$$
\mathrm{C}=\mathrm{A}\left[\left(\mathrm{M}_{\mathrm{t}}+\mathrm{M}_{\mathrm{p}}\right) / \mathrm{M}_{\mathrm{f}}\right]^{\mathrm{B}} \text {, }
$$

where $\mathrm{M}_{\mathrm{f}}$ is the "mass of the smallest debris considered," which corresponds to $0.26 \mathrm{~kg}$, or a diameter of $0.1 \mathrm{~m}$, the smallest size in the JSC Catalog. Inserting the kernel of Eq. (6) into the full Eq. (2) produces the plot of fragment production as a function of $M_{p}$ and $M_{t}$ shown in Fig. 8 . This plot for fragment production as a function of projectile and target size resembles the plot of catastrophic collisions in Fig. 4, although the peaks are accentuated by the greater fragment production in collisions between large particles.

Figure 9 shows that the integrated contribution from smaller objects is significant. The contributions to fragment production integrated over target size is roughly the same from bins of all projectile sizes larger than $0.6 \mathrm{~m}$, except that from the largest ofjects, which is an order of magnitude smaller. The cumulative integral over projectile size reaches about $50 \%$ of its full value of 102 fragments by a projectile diameter of about $1.6 \mathrm{~m}$. This value is larger by $25-70 \%$ than the value of 60-80 fragments per collision given in the SAB report, but is based on a significantly different, hypothetical cascaded future debris distribution. to Figure 10 shows the Fragment production rate as a function of target diameter, which increases rapidly with $\mathrm{M}_{\mathrm{t}}$ as a result of collisions of large targets with projectiles large enough to be catastrophic.

The JSC note on "Parts Creation" in Attachment A gives an alternate procedure based on a "standard NASA equation to determine the number of objects greater than a given mass"

$$
\mathrm{CN}=0.4478\left(\mathrm{Mf}_{\mathrm{f}} / \mathrm{M}_{\mathrm{e}}\right)^{-0.7496} \text {, }
$$

in which $\mathrm{M}_{\mathrm{f}}$ is the "mass of the smallest debris considered" $0.26 \mathrm{~kg}$, corresponding to a diameter of $0.1 \mathrm{~m}$, and $\mathrm{M}_{\mathrm{e}}$ is the "mass of the ejecta (i.e., total mass for catastrophic collisions)." This expression involves only aggregate quantities, so it can be evaluated directly with the quantitities calculated above. Substituting the JSC average masses of Table I into Eq. (1) gives

Table II. Fragments from average mass of catastrophic collisions

$\begin{array}{lllll} & \text { JSC all coll } & \text { JSC catastr (CN) } & \text { SAB catastr } & \text { difference } \\ \text { avg. mass } & 2271 & 2007 & 2103 & 5.8 \% \\ \text { fragments } & 403 & 368 & 102 & -206 \%\end{array}$

The average JSC mass for all collisions is that given below Table 1 of Attachment $A$ and in Table I above. The calculated value of 403 fragments for all collisions corresponds to using JSC's average mass of $2271 \mathrm{~kg}$ from Table I in Eq. (7). However, Fig. 7 shows that only about half of all collisons are catastrophic, so it is inappropriate to use this full mass in estimating fragment production. Using instead JSC's mass of of $2007 \mathrm{~kg}$ for catastrophic colisions from 
Table I in Eq. (7) gives the value of 368 fragments in the middle column. The third column corresponds to the SAB's calculated average mass of $2103 \mathrm{~kg}$ in Table I, which is calculated in an integrated average of Eq. (6) that produces the 102 fragments per collision shown.

The apparent discrepancy in fragments between the JSC and SAB calculations of a factor of $368 / 102 \approx 3.6$ is partly definitional and partly substantive. JSC's average of 368 fragments is only appropriate for the $52.4 \%$ of the collisions that are catastrophic, so the average number of fragments per collision of all types is

$$
\mathrm{CN}=368 \times 0.524=193 \text { fragment } / \text { collision, }
$$

which is only a factor of $193 / 102 \approx 1.9$ larger than the value from the SAB calculation. This corrected value of 193 fragment / collision is used for comparisons below. When necessary to avoid confusion, the value of 368 is referred to as the "average number of fragments per catastrophic collision." The residual difference of a factor of 1.9 is due primarily to the difference in the choice of exponent $B$, which is discussed after cumulative fragment production.

JSC cumulative fragment production. Figure 2 of Attachment A shows JSC's estimates of cumulative fragment production versus cumulative mass in [catastrophic] collisions. While the calculations that produce the chart are not presented, the implied conclusion that the fragment production is almost linear in the mass involved is worth examining, which can be done with the tools described above. Although Eq. (7) for $\mathrm{CN}$ applies to the total mass involved in catastrophic collisons, Fig. 2 of Attachment A is apparently generated by substituting Eq. (7) for $\mathrm{Z}$ in the average of Eq. (2). Figure 11 tests that by comparing the result of doing so with the result gernerated by useing Eq. (6) with $B=0.7496$ to estimate fragment production. The curves are similar and displaced by a small amount, which indicates a small multiple difference.

The ratio of the two curves is almost precisely 1.34 . That is almsot precisely the ratio of the JSC and SAB A coefficients, which is $0.0 .4478 /(1 / \mathrm{B}-1)=0.4478 /(1 / 0.7496-1)=1.343$. Figure 12 shows the A coefficients from the SAB, JSC, and FASTT DNA models. They cross at $B \approx 0.65$, but the JSC $A$ is constant, so it remains above the SAB and FASTT coefficients (i.e.,. the JSC disctibution is not normalized), which is the source of the factor of 1.34. Thus, it is clear how JSC Fig. 2 is generated.

With that understanding, it is possible to compare JSC and SAM versions of JSC Fig. 2 by changing the $\mathrm{SAB}$ exponent back to 0.62 and plotting the resulting cumulative fragment productions as a function of cumulative mass involved in producing them, as is done in Fig. 13. The lower curve is the the $S A B$ curve for $B=0.62$, which is roughly linear although it falls off for large fragments and saturates at about 102 fragments, as discussed in Table II. The top curve is the JSC curve from using Eq. (7) as a kernel in Eq. (2). It asymptotes to about 264 fragments, which is a factor of 2.6 larger than the SAB value for all large fragment sizes. From the above discussion it is clear that this factor is made up of a factor of 1.9 due to the use of $B=0.75$ rather 
than the experimental value of 0.62 and a value of 1.34 due to improper normalization relative to FASTT, i.e., non-conservation of mass. The product of those two factors is $1.9 \times 1.34 \approx 2.6$, which is precisely the factor that separates the two curves.

In the JSC currve an asymtote is shown for the geometric mean number of fragments at 403. As noted in Table II, that corresponds to using the mass for all collisions; however, only half are catastrophic. When the JSC mass of $2007 \mathrm{~kg}$ in the second column is used, Eq. (7) produces 368 fragments as shown. As discussed in Eq. (8), when that value is corrected for the fact that only $52.4 \%$ of the collisions are catastrophic, the resulting fragment production rate is 193 fragments per collision, which is a factor of 1.9 greater than the SAB value due to the use of the higher $\mathrm{B}=0.75$, as discussed above.

While there is no new information in JSC Fig. 2, the SAB recalculation of it in Fig. 13 does provide the information that for most fragment sizes, the cumulative fragment production is roughly a linear function of cumulative mass. Thus, apart from the large objects, for which fragment production saturates, the derivative of the number of fragments with respect to that of the cumulative mass is about constant, which means that objects of all masses and sizes produce comparable numbers of fragments.

The variation of fragments per collison with $B$ can be assessed by changing the value of $B$ in the kernel of Eq. (16) used in the averaging of Eq. (2). Figure 14 shows that this variation is fairly strong. From a value of about 60 fragments per collision at $B=0.55$, it increases to a value of about 240 at $B=0.8$. Its value is about 197 at $B=0.75$, which is close to the JSC value of 193 in Eq. (8). However, the review of DoD impact experiments in a companion paper shows that a value of $B=0.75$ is not consistent with the DNA test data, and that the mean value of $B=$ 0.62 better characterizes the full data set. 12 The SAB calculations are best represented by the DNA average value of $B=0.62$, for which the discrepancy between the corrected JSC and SAB estim ates is a factor of $193 / 102=1.9$, as discussed above.

Figure 11 also shows a curve labeled FASTT, which is the semi-empirical curve developed by DNA to model the DNA experimental results cited by JSC. ${ }^{13}$ It lies slightly below the $S A B$ curve at small $B$, crosses it at about $B=0.65$, and rises more sharply for larger values of $B$. Of interest here is that the curve developed by DNA to model the DoD data gives a slightly lower value of $B$ than the average value of $B=0.62$ used in the $S A B$ calculations, which represents an independent test of the SAB's reduction of the DNA data and a confirmation of its estimate of the number of fragments produced.

Thus, it appears that different choices of the exponent in the fragmentation kernel are the dominant factor in explaining any discrepancies between the JSC and SAB calculations. The source of the $S A B$ value of $B$ is the average of the experimental results in the summary DNA report. The JSC kernel is described as the "standard NASA equation to determine the number of 
objects greater than a given mass." It is not otherwise discussed or explained in the documents referenced in Attachment A, and does not agree with the DNA data or with the FASTT model derived to model it.

Summary and conclusions. The JSC Attachment contains much of the information to complete the comparison of SAB and JSC estimates of fragment production. It gives a useful table of collision frequency, NASA's equation for fragment production, and some references, which are used as the basis for the comparisons made above. This information makes it possible to understand and achieve agreement with JSC's average masses for all collisions and to discuss the discrepancies in the fragment production rate estimates based on them. The agreement on the average mass involved in all collisions is on the order of $1 \%$, which is in the noise. The agreement on average masses in catastrophic collisions is on the order of $6 \%$, which is within the uncertainties in averaging proceedures, once it is recognized that only about $52 \%$ of the collisions in JSC's table are catastrophic and the JSC rates are corrected for that fact.

The empirical fragment distribution kernels are reviewed and the proper metheds for averaging them over debris and collision frequency distributions are derived, leading to a prediction of 102 fragments per collision for the highly cascaded distributions presented. While the JSC substitution of average masses into fragmentaion kernels for the estimation of fragment production rates is technically incorrect and sometimes misleading, the agreement with JSC on the corrected fragment production rates at that level is within a factor of two and readily traceable to the different parameters used in the two calculations. For the JSC collision frequencies, the JSC production rate overestimates that from the SAB study by about $90 \%$ due to the choice of the parameter used in the fractionation kernel. The SAB results are also compared to the predictions of the FASTT model developed by DNA to model the DoD impact experiments, which predicts a lower number of fragments per collison than that calculated by the $\mathrm{SAB}$ for the average parameters from the DNA test series.

This comparison was stimulated by the apparent contradiction between the JSC statement that the average debris collision would "produce about 480 fragments larger than $10 \mathrm{~cm}^{\text {" } 14}$ with the result in the SAB report that the average number of fragments per collision is $60-80.15$ For the conditions specified by JSC for this comparison, the number of fragments for JSC's "standard equation" is 368 per catastrophic collision, or 193 per collision, which is only a fraction of $193 /$ $480=40 \%$ of the 480 claimed in the literature, but still a factor of $193 / 102 \approx 1.9$ greater than the value calculated by the SAB on the basis of DoD-DNA parameters. The majority of the discrepancy between the two results can be traced to a factor of 1.9 in fragments per catastrophic collision, which is due to JSC's use of a fragmentation formula that is inconsistent with the DoDDNA test data and a further factor of two due to the confusion between catastrophic and total collisions in JSC's statement. 
Overall, a more accurate summary would appear to be that debris collisions produce an average of about 102 fragments, which can be directly related to JSC's estimate through a simple series of corrections: multiply the JSC $\approx 480 \times 403 / 480$ [normalization] $\times 368 / 403$ [catastrophic] $x 0.524$ [catastrophic / total] $\times 1 / 1.9[B=0.62] \approx 100$, in agreement with the $S A B$ value of 102 . That produces a factor of 4.8 reduction in the JSC estimate to a level of about 100 fragments per collision, at which fragmentation would produce little cascading. The remaining discrepancy is within the errors expected for the spuriously cascaded distributions used for comparison.

Acknowledgment. The author would like to acknowledge the cooperation of Dr. Nicholas L. Johnson of the NASA Johnson Space Center for providing the collision frequency table on which this comparison is based and the comments and suggestions of his SAB colleagues on the result. 


\section{References}

1. N. Johnson, NASA JSC letter of 2 May to W. Ballhaus, Vice-Chairman, USAF SAB.

2. G. Canavan, O. Judd, and F. Naka, "Comparison of Space Debris Estimates," SAB report.

3. N. Johnson, telecon with W. Ballhaus.

4. G. Canavan, O. Judd, and F. Naka, "Comparison of Space Debris Estimates," op. cit., Fig. 3.

5. D. Kessler 1000 D. Kessler, Collisional Cascading: the Limits of Population Growth in Low Earth Orbit," Adv. Space Res. Vol. 11, No. 12, pp. 1263-1266, 1991, p. 1265.

6. D. McKnight, R. Maher, L. Nagl, "Fragmentation Algorithms for Strategic and Theater Targets (FASTT) Empirical Breakup Model," DNA/SPSP report January 1994 (Kaman Sciences Corporation, Washington)

7. G. Canavan, "Analysis of DNA Impact Test Data," Los Alamos LA-UR-97-draft, July 1997.

8. D. McKnight, N. Johnson, M. Fudge, and T. Maclay, "Analysis of SOCIT Debris Data and Correlation to NASA's Breakup Models," NASA 9-19215 JSC-SNC (Kaman Sciences Corp. July 1995).

9. D. McKnight, R. Maher, L. Nagl, "Fragmentation Algorithms for Strategic and Theater Targets (FASTT) Empirical Breakup Model," op. cit.

10. G. Canavan, O. Judd, and F. Naka, "Comparison of Space Debris Estimates," op. cit.

11. G. Canavan, O. Judd, and F. Naka, "Comparison of Space Debris Estimates," op. cit., p. 21, Eq. (2).

12. G. Canavan, "Analysis of DNA Impact Test Data," op. cit.

13. D. McKnight, N. Johnson, M. Fudge, and T. Maclay, "Analysis of SOCIT Debris Data and Correlation to NASA's Breakup Models," op. cit.

14. D. Kessler Adv Sp Res. D. Kessler 1000 D. Kessler, Collisional Cascading: the Limits of Population Growth in Low Earth Orbit," op. cit., p. 1265.

15. G. Canavan, O. Judd, and F. Naka, "Comparison of Space Debris Estimates," op. cit., p. 21. 
Fig. 1. coll per cent $2 d$

Fig. 1. Collisions per century

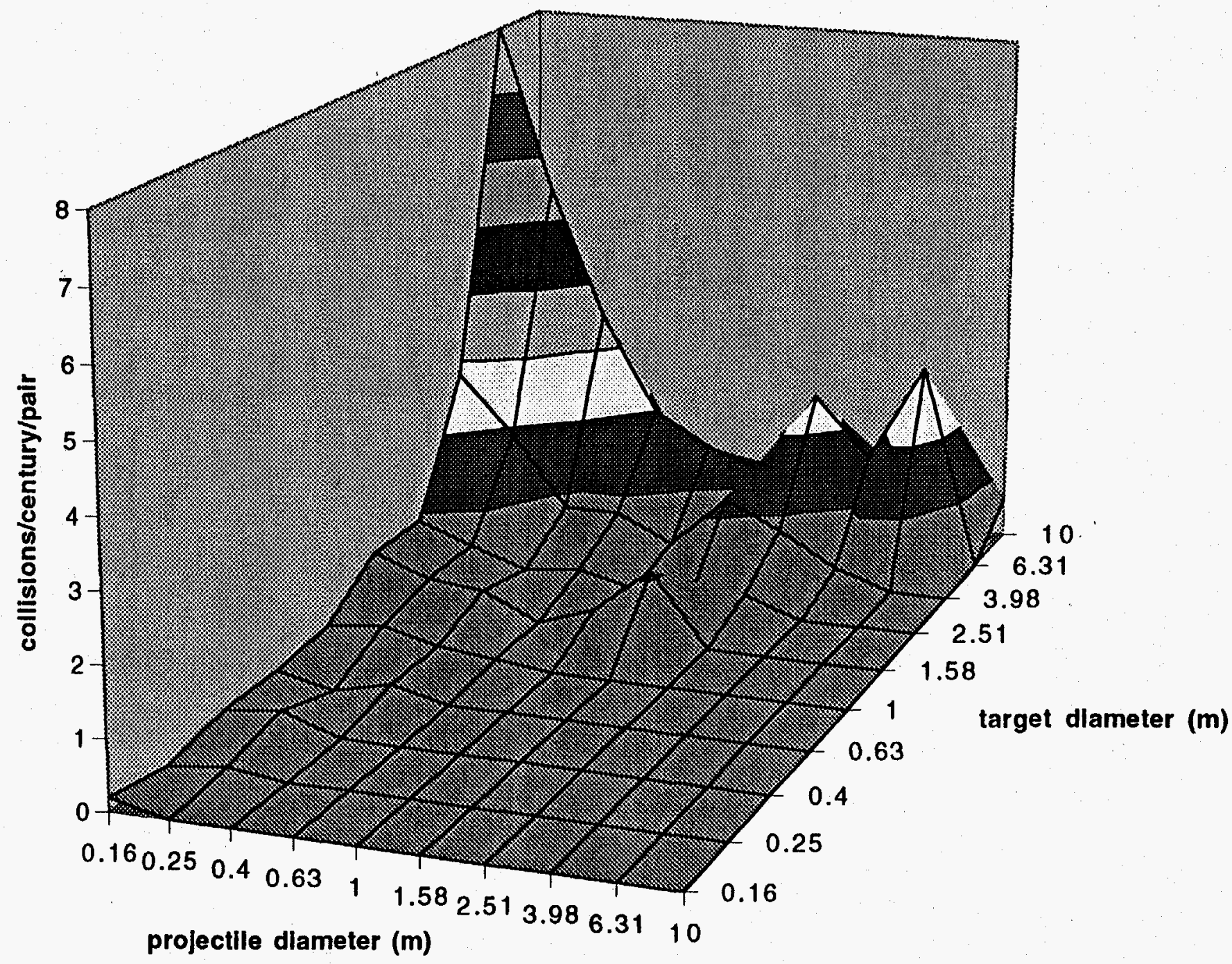


Fig. 2. Collisions versus projectile size

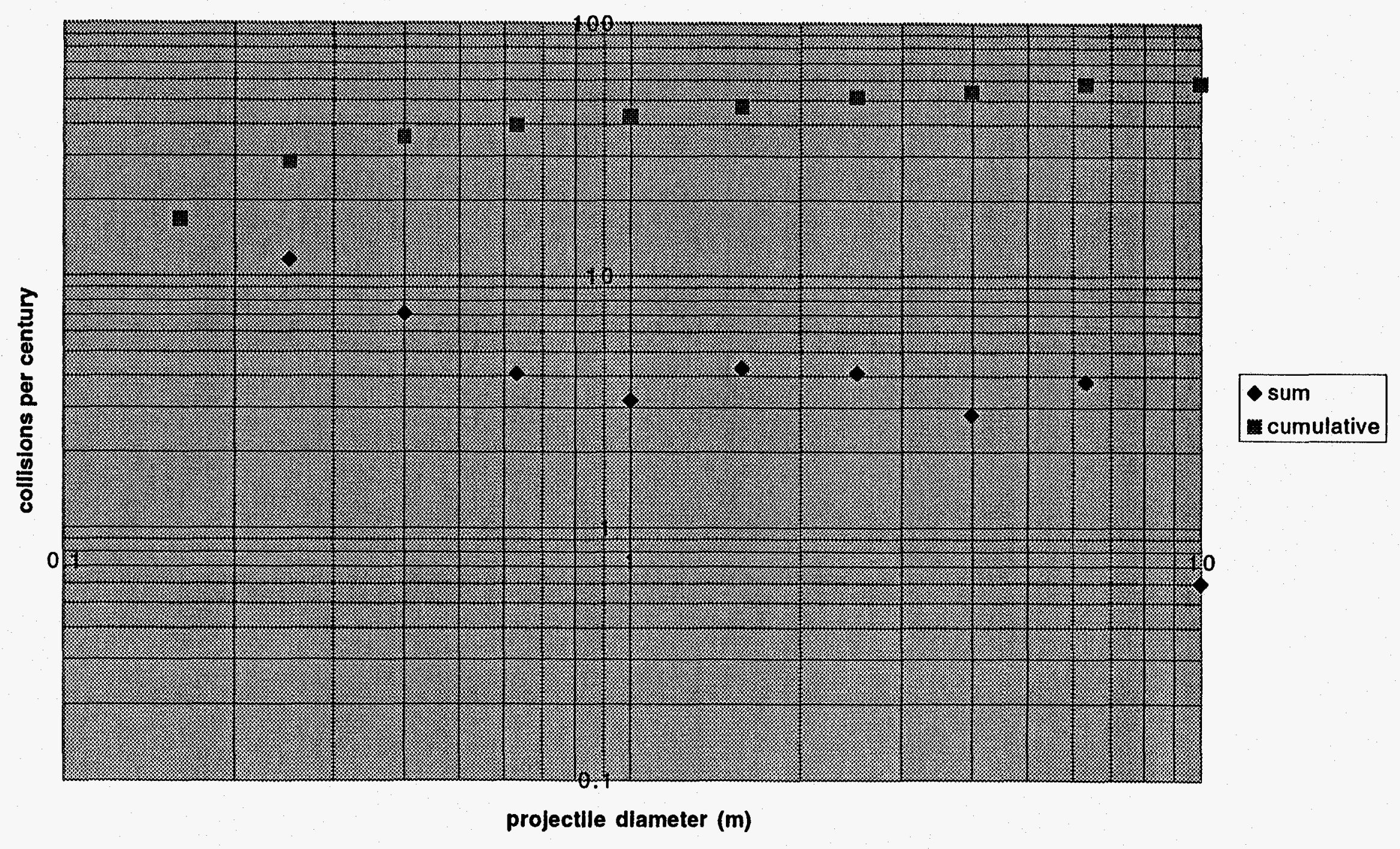


Fig. 3. Collisions versus target size

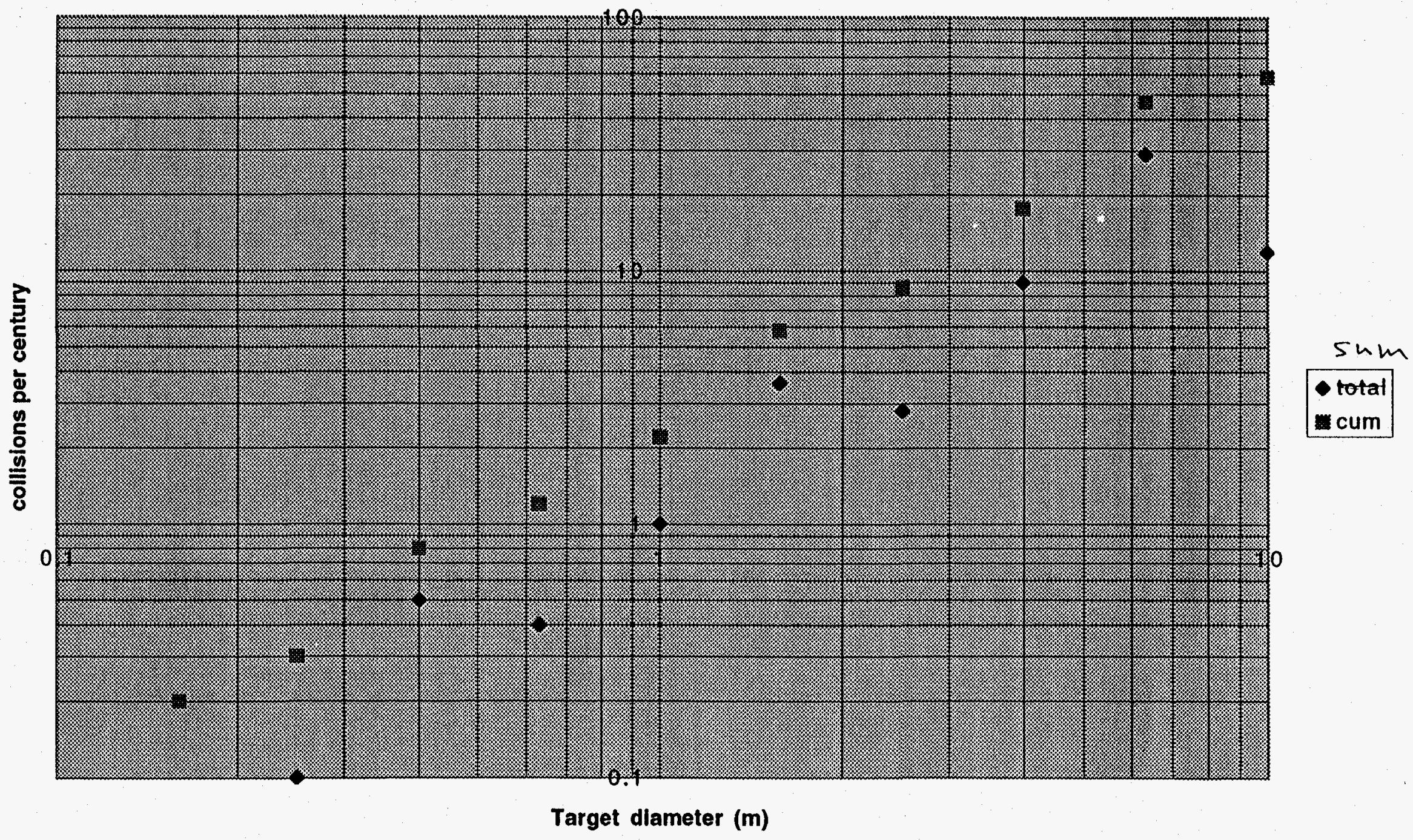


Fig. 4. Catastrophic collisions per century

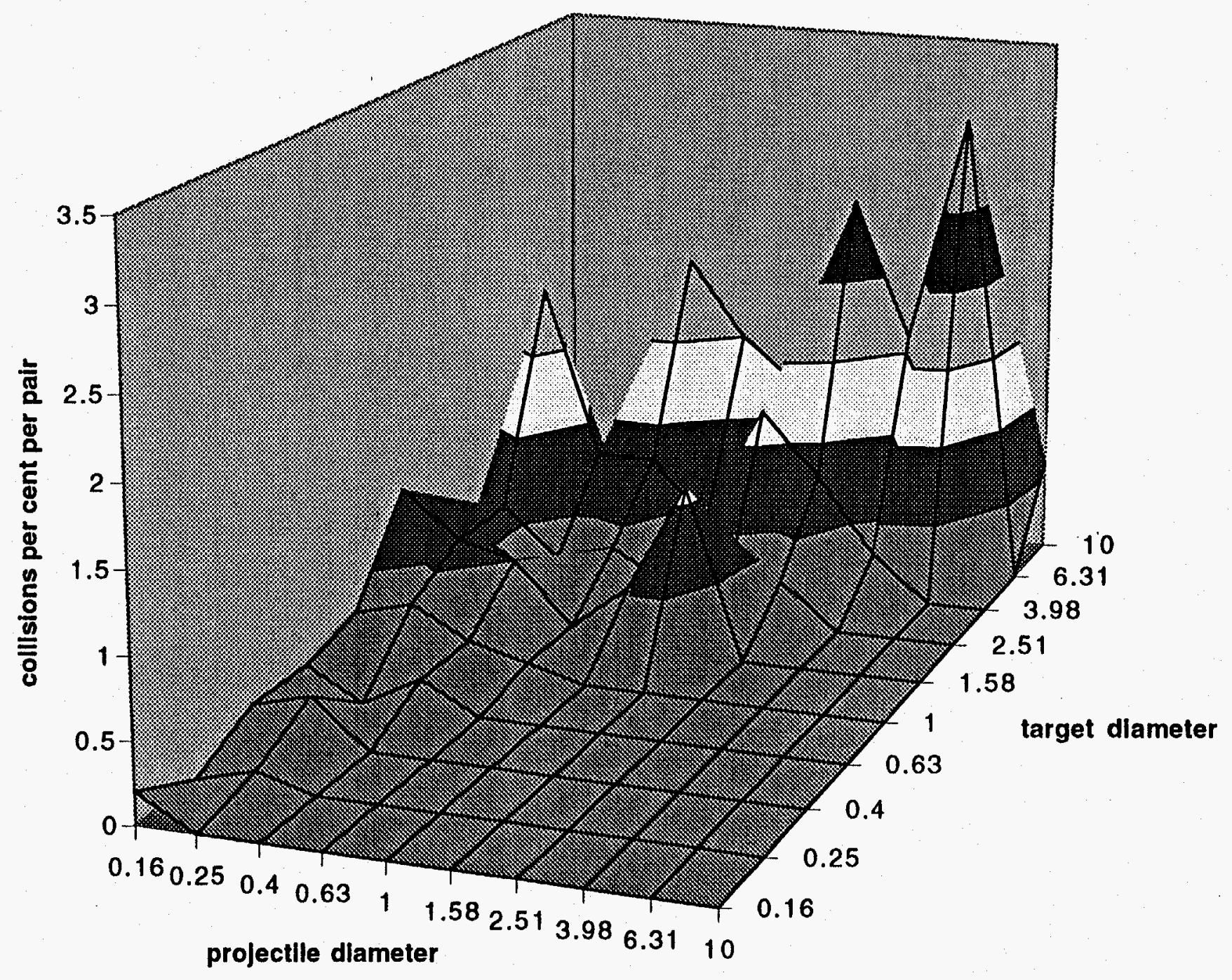


Fig. 5. Catastrophic collisions versus projectile size

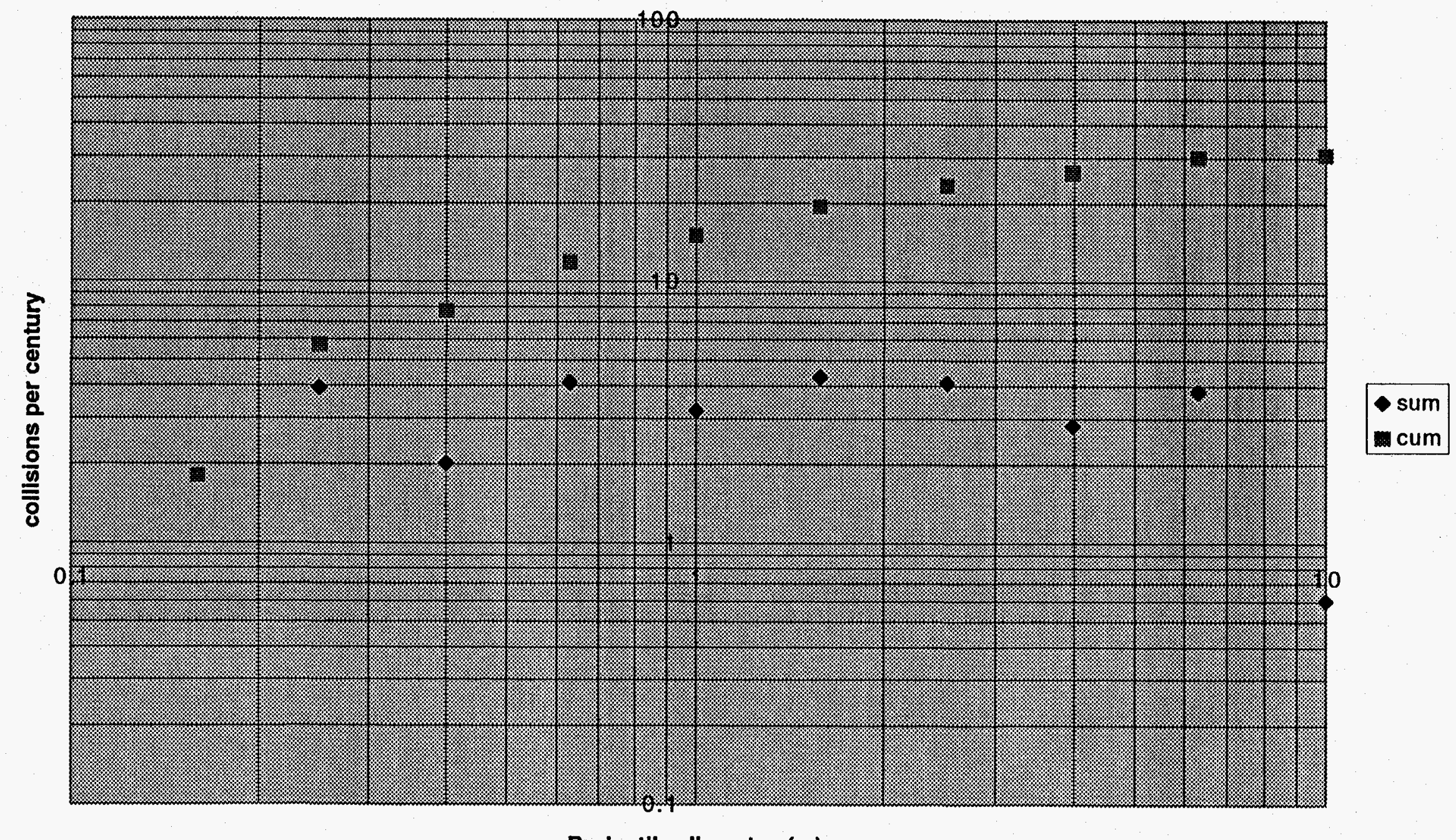

Projectlle dlameter (m) 
Fig. 6. Catastrophic collisions versus target size

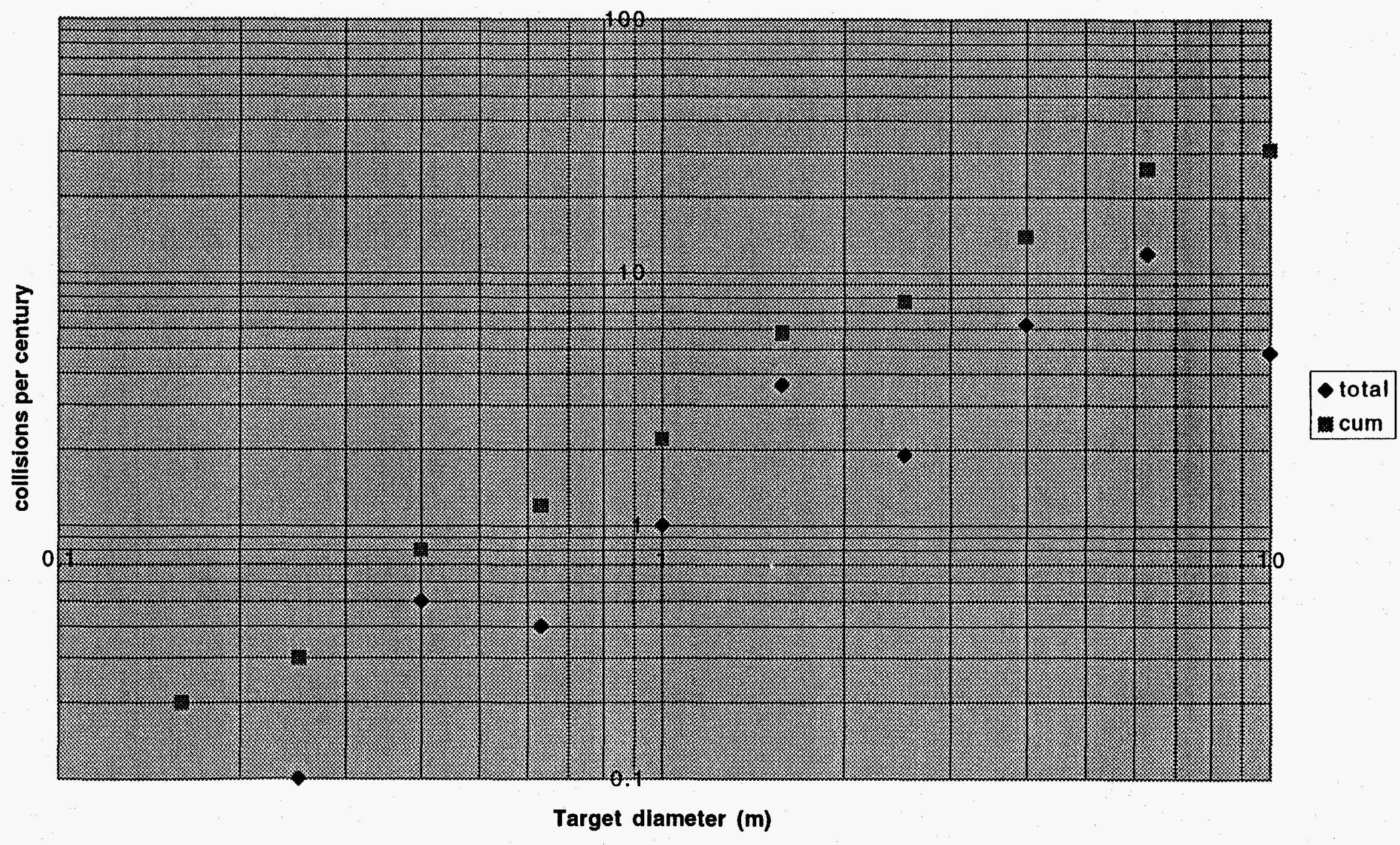


Fig. 7. Average mass

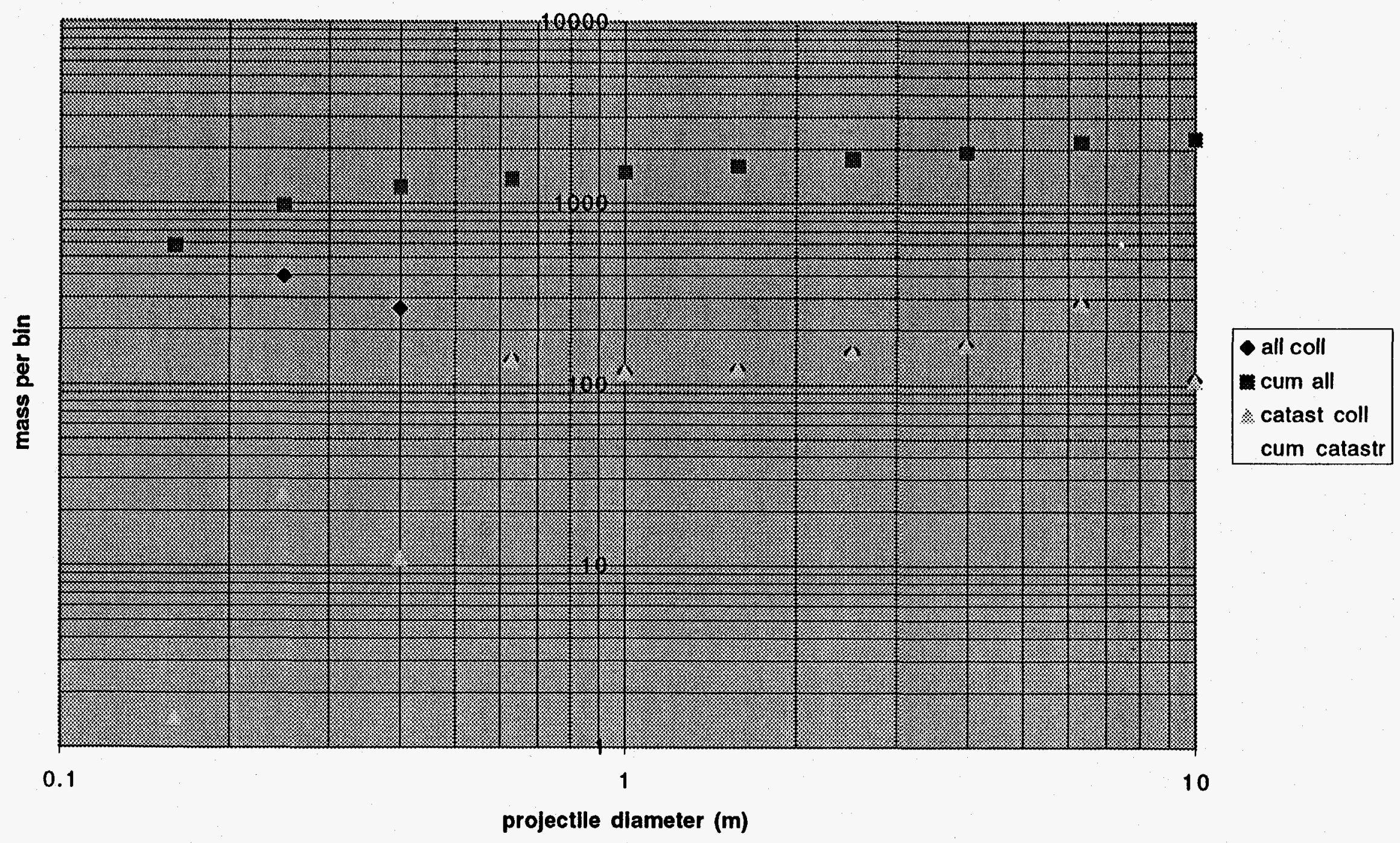




\section{F 8 Frag $p$ cent $p$ bin}

Fig. 8. Fragment production per century per bin

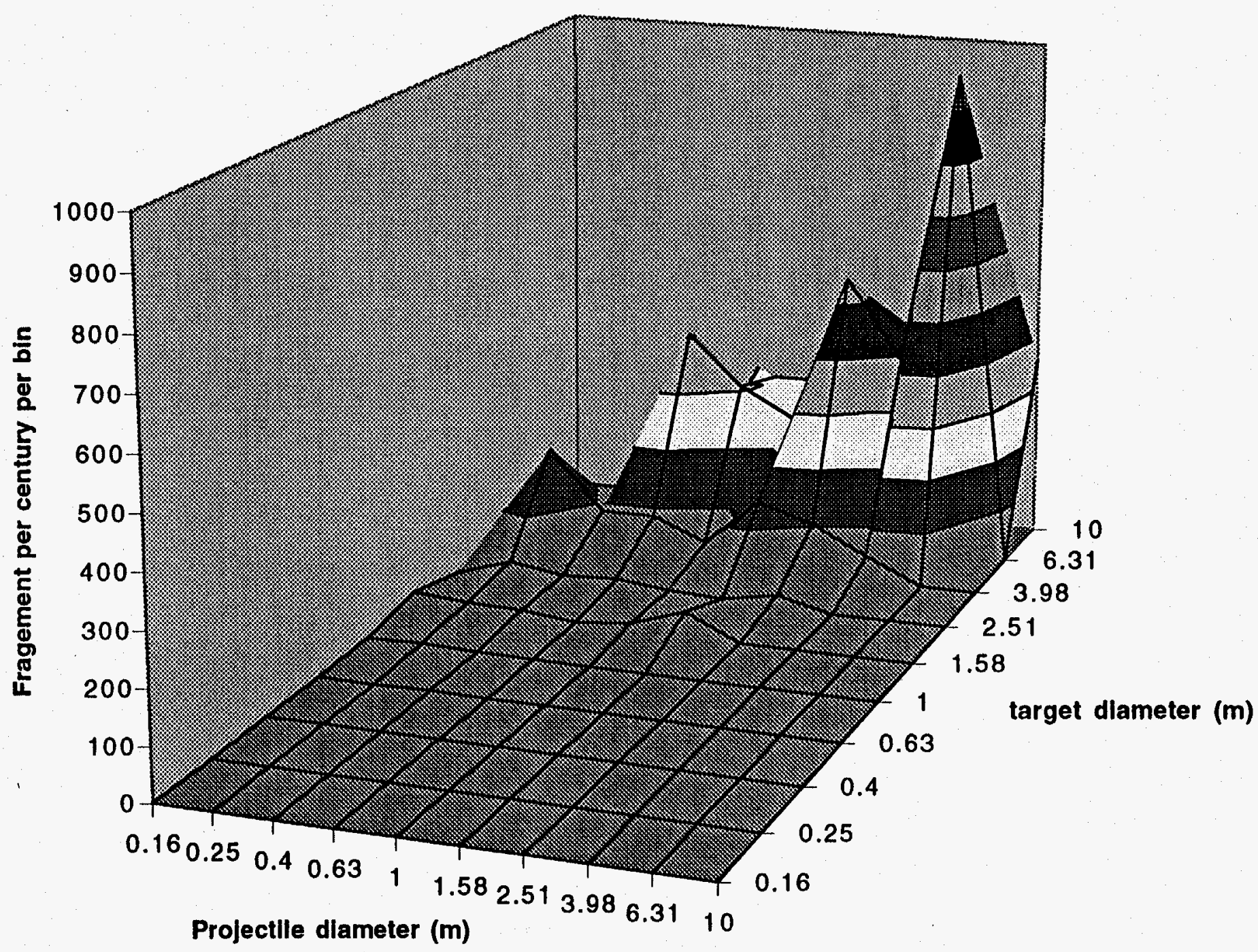




\section{Fig. 9. Fragment production versus projectile size}

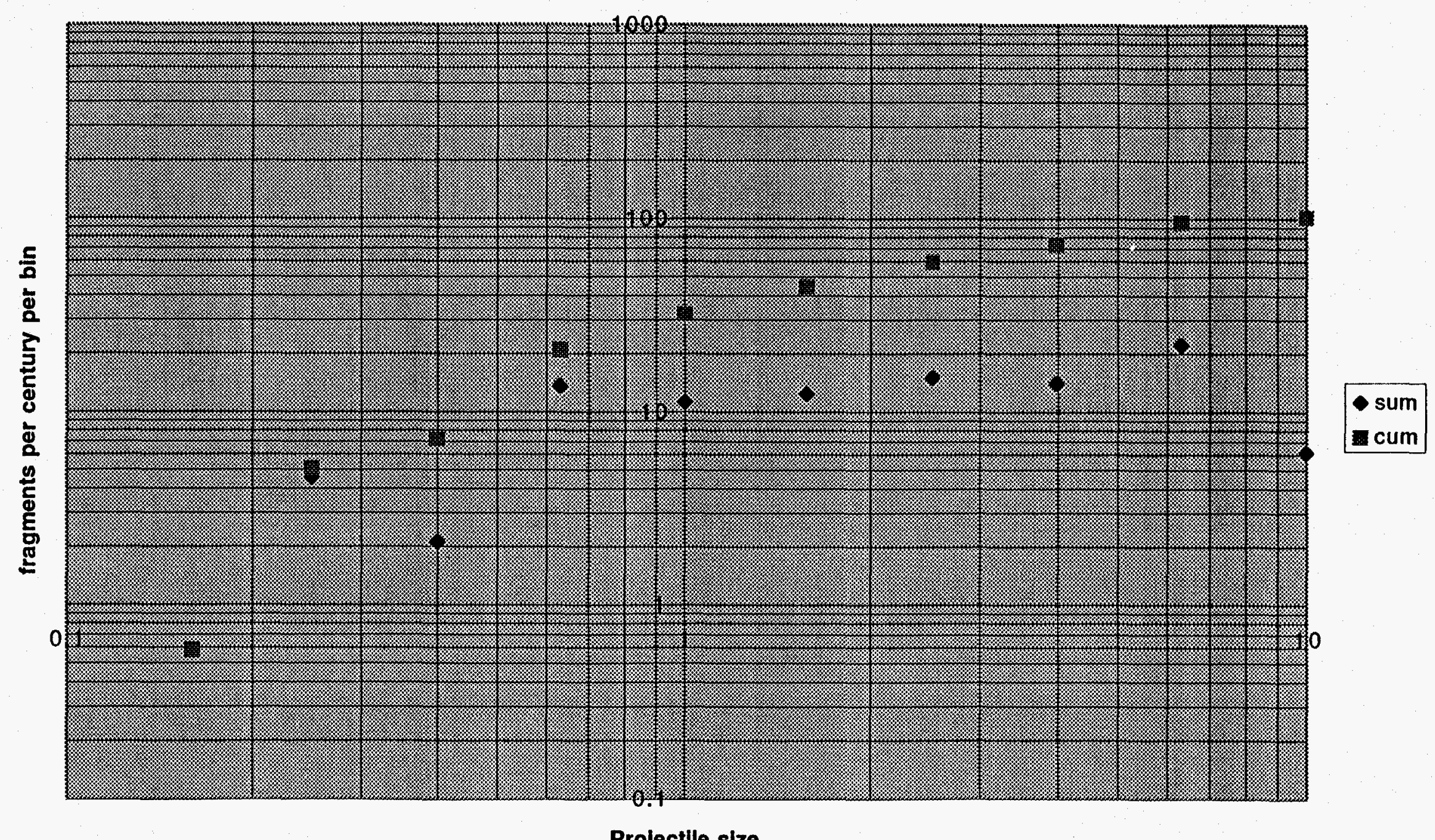

Projectlle size 
Fig. 10. Fragment rate versus target size

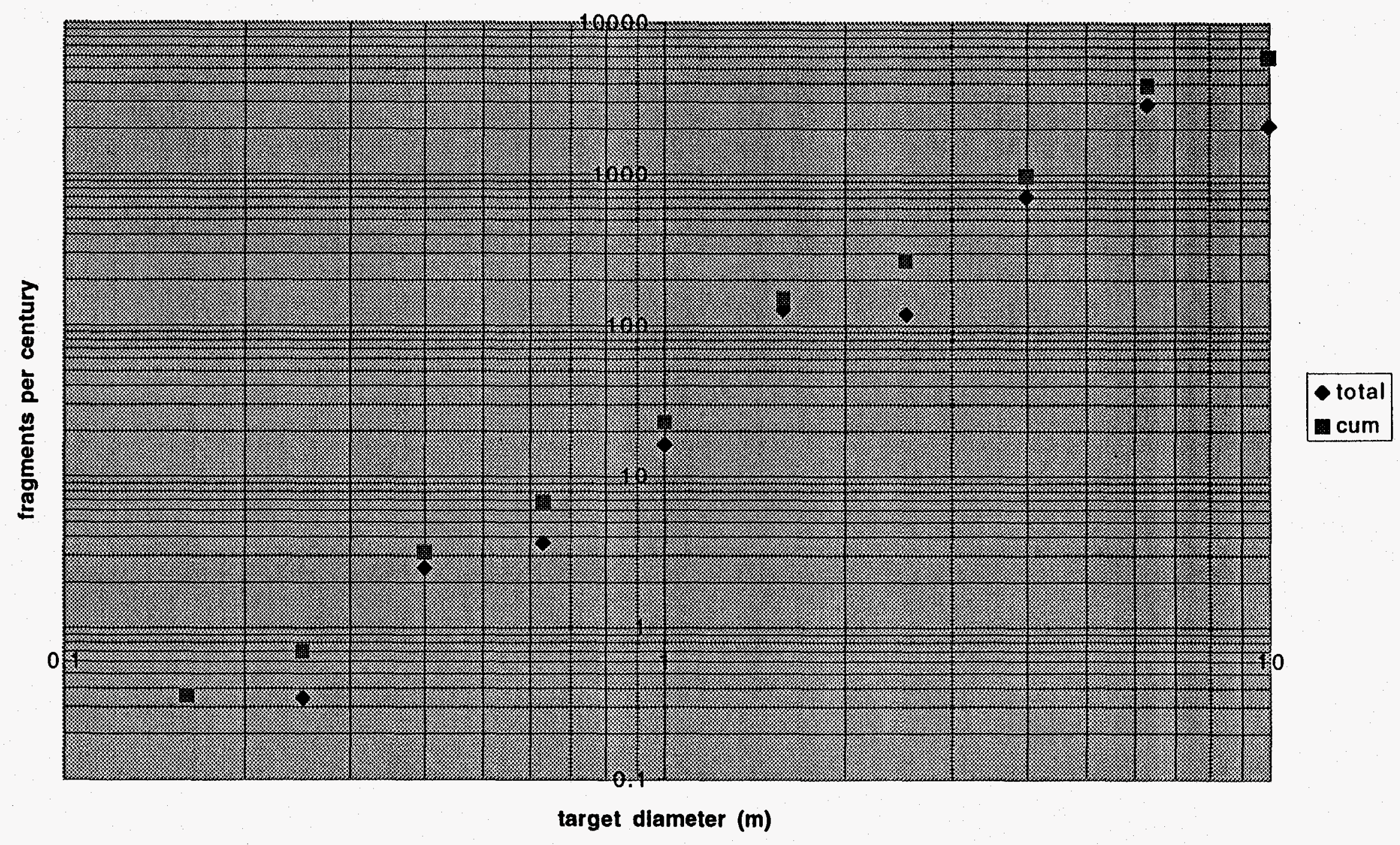


Fig. 11.Cumulative fragment production vs projectile size

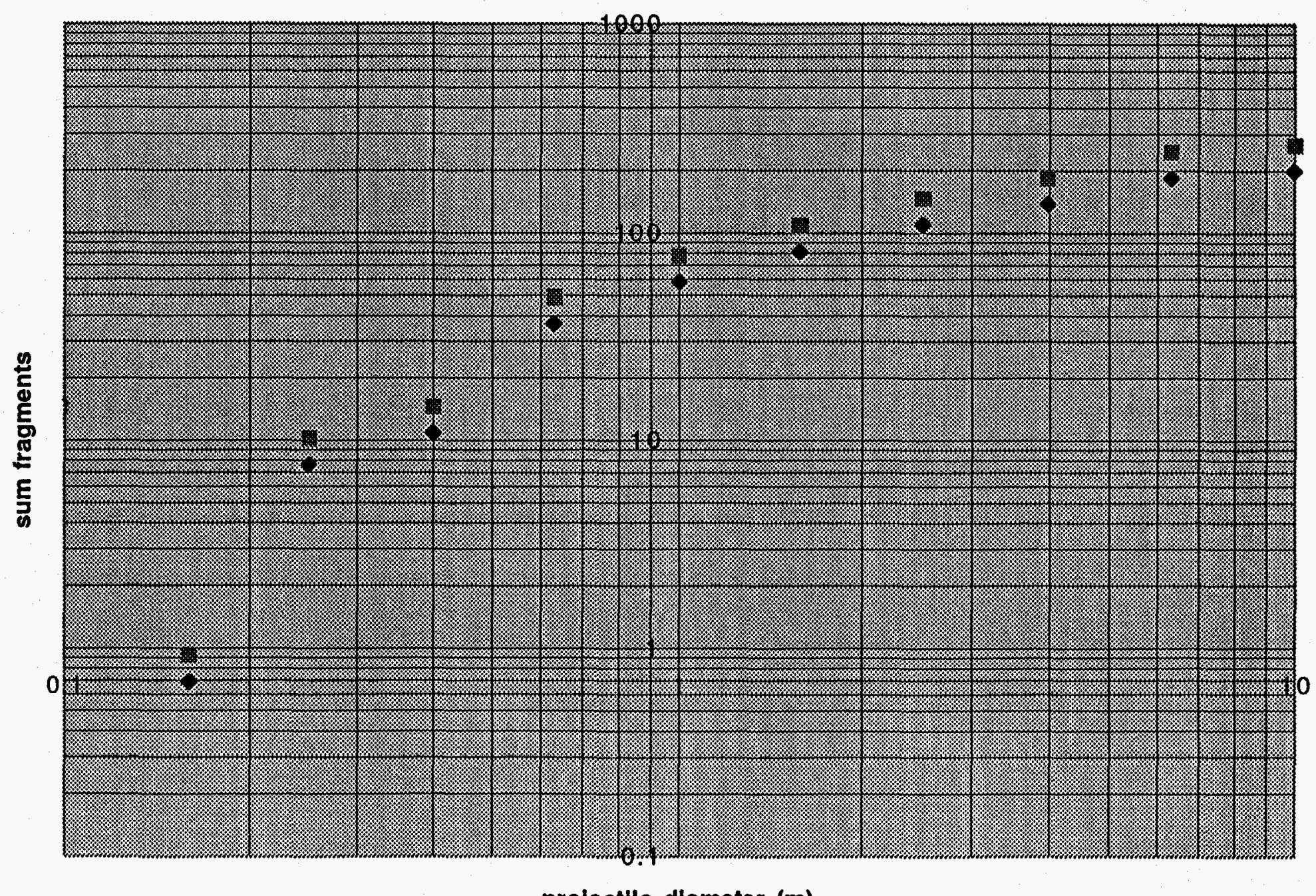

projectile dlameter (m) 
$F 12 A$ vs $B$

Fig. 12. A coefficients versus $B$

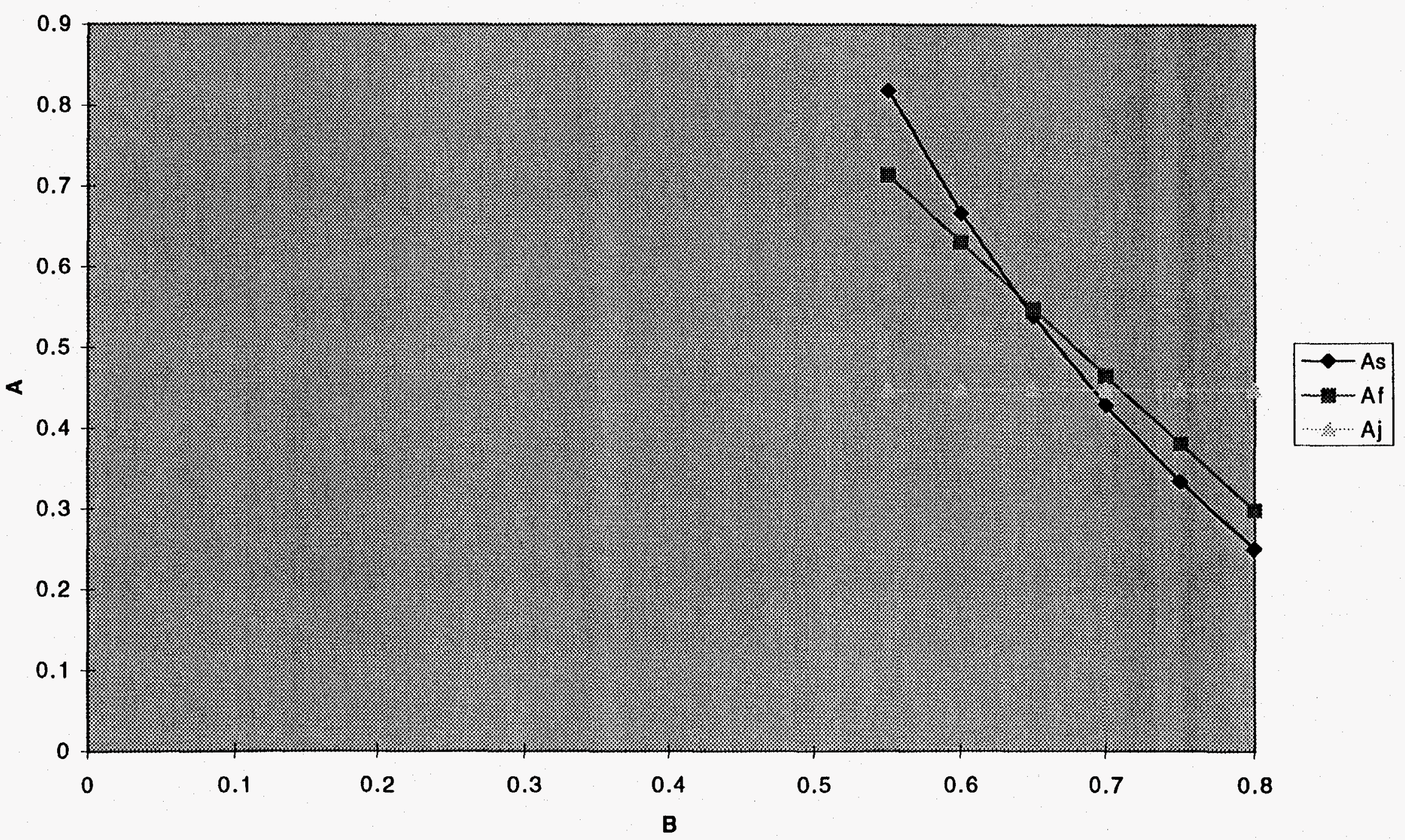


F 13. cum fr vs cum $m$

Fig. 13. Cumulative fragments vs cumulative mass

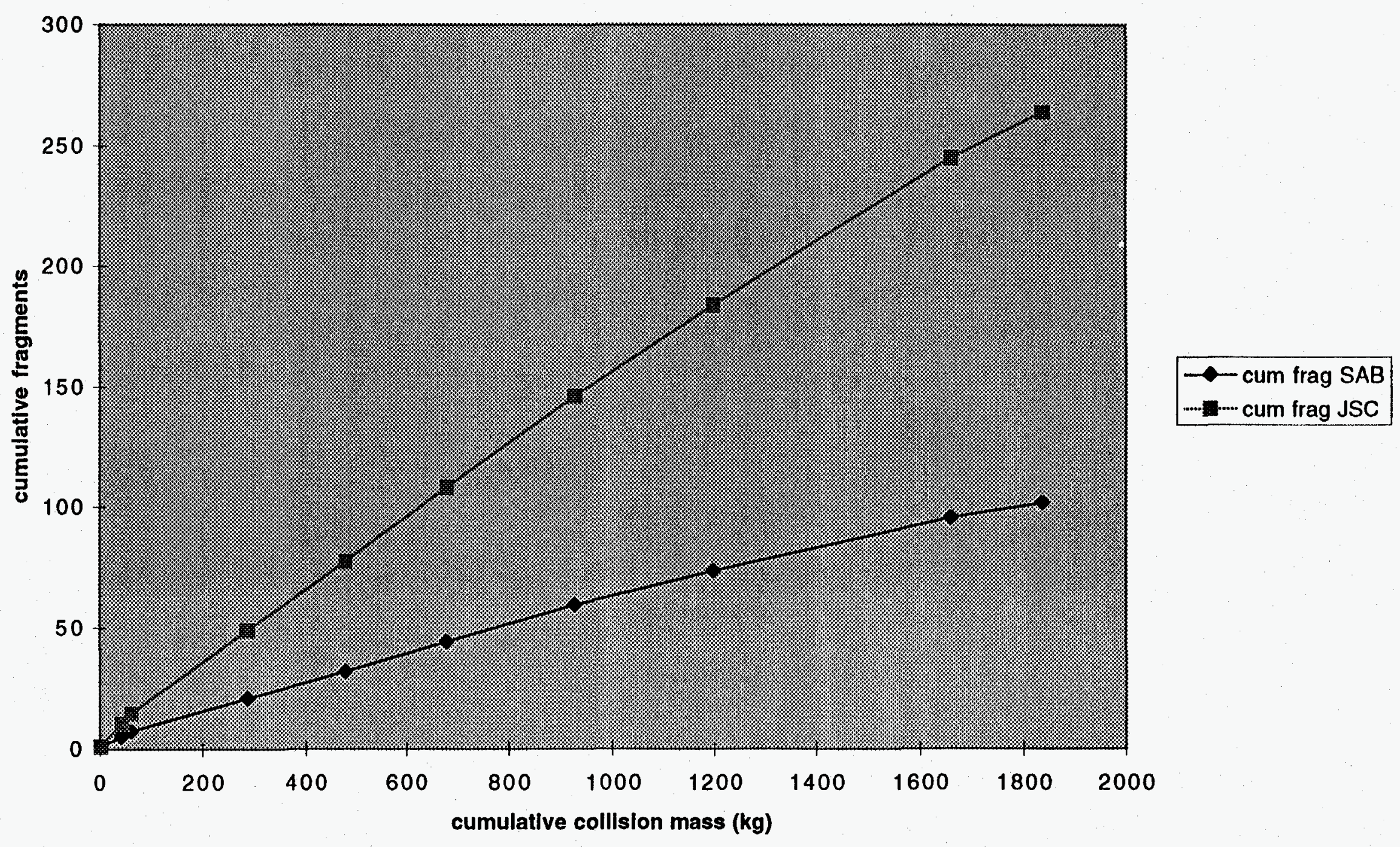


F 14 frag $p$ tot col $v$ B

Fig. 14. Fragment per total collisions versus $B$ exponent

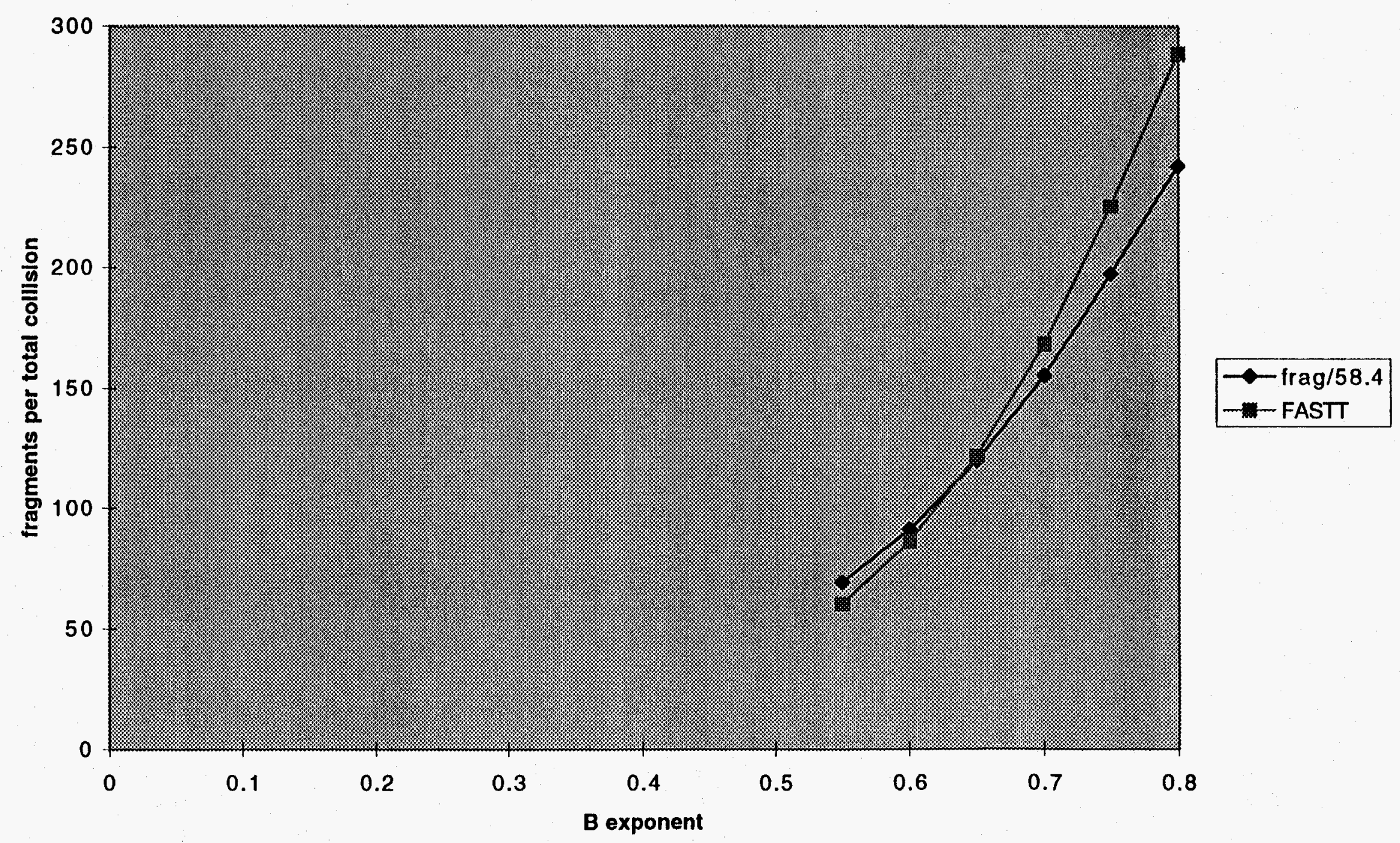


85-02-1997 16:26

7134835276

NASA JSC SN3 BLDG 31

P.01

N $15, A$

TELECOPY

sond To: /Dr. Willam Ballhaus
301-097-8916 /Mr. Natalle Crawford
310-481-7038

At. Col. James Borko 703-605-6242

Dr. Oroo Canavan 505-867-3400/3644

Mr. Louls Ponch

Mr. Coproe Lovin

202-358-2940

Mr. Joseph Loftus

$284-483-6838$

Date: 2 May 1907

From: Nlcholas L. Johnoon NA8A Johnson Epaso Contor BN3 Houston, TX 77088

Phone: 281-483-8313

FAx: $281-483.6278$

Number of Pages (Including Cover Sheot): 7 
Nattonal Aoronautics and

Spaco Administration

Lyndon D. Johneen Epace Comtor

2101 NASA Roed ?

Houston, Toxas 77058-3896

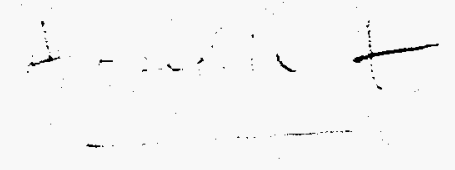

2 May 1997

D. Wilen Bethey

Mre. Nentla Crawtord

4 Col. James Earto

Di. Grog Cormen

USAF Solomitio Advioony Board

Wontretion. DC

Sublact NASA inputs to Pien for Cloure of Otbued Debris leaven between the SAB and NASA

\section{Derr sise and Maden:}

Re the recomt communications among SAB and NASA perconnol concerning the eublect otted

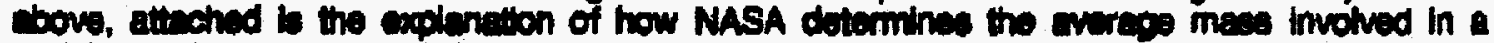

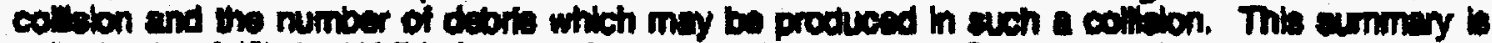

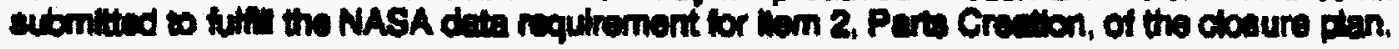

Aeguding them 8, Caeced, NASA whes to relterute our recommendation of the ecceptance of

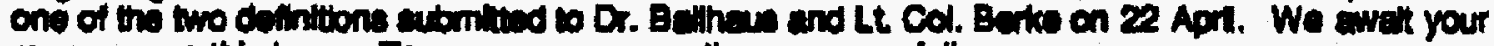

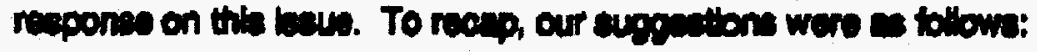

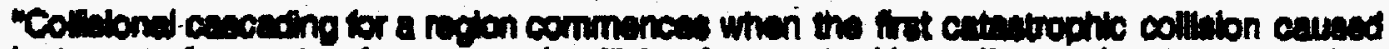

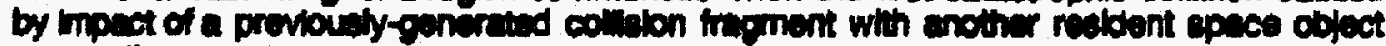
pcoure."

or

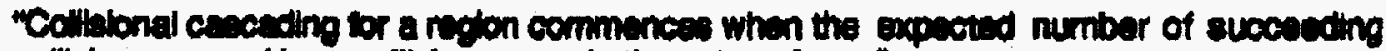

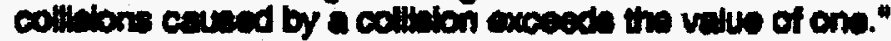

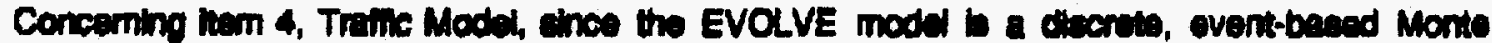

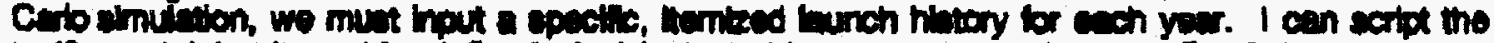

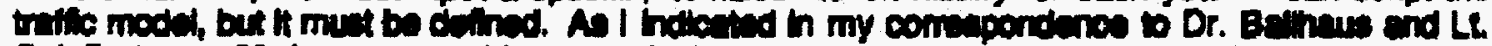

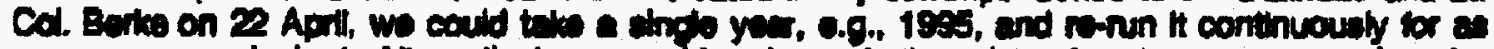

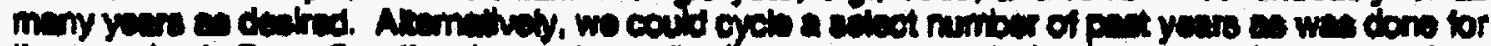

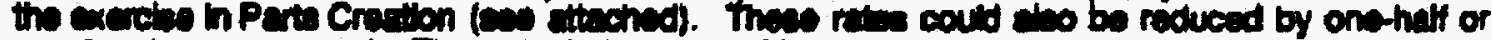

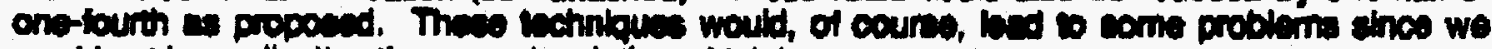

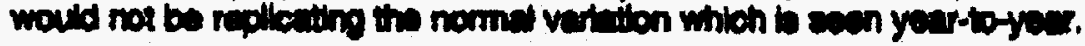




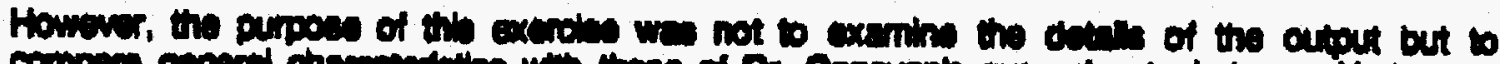

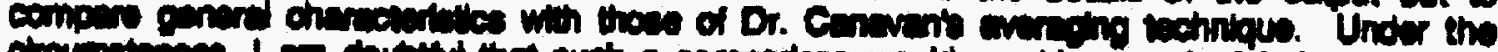

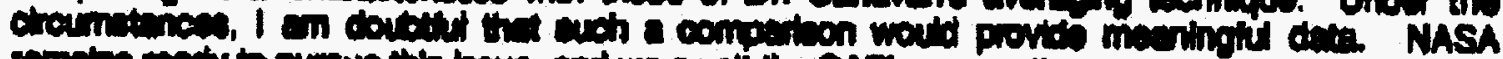

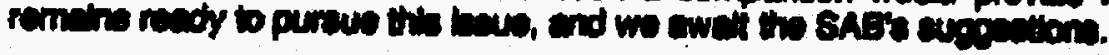

Einowry,
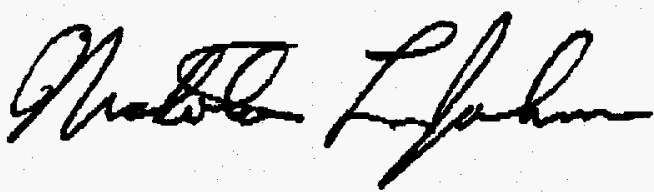

Notroles L. Jom

Chint Solentut bor Otow Dorit

MBA dohnoon Spese Contor

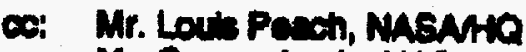

Mr. Geory Lond, NASMAO

M. doneph Lofun, Jt, NASNASCEA 


\section{Parts Croation}

The objoctives of this exorclas were to determine (1) the "everape" amount of mase involved in a netural colliden and ( 2 ) the number of lame dobris (dilameters greater than $10 \mathrm{om}$ ) created in euch a colliyon. This minimum dabris szo is important since it is generally suficient to induce

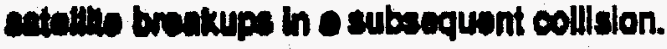

Mathodplery. Ten 100-year Monts Carto runs of the EVOLVE code wore executed with a bese cposh of Lanuary, 1003. A tratile model repeating the hittoric space leunches of 1988-1983

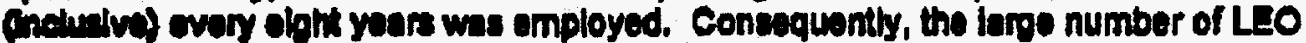

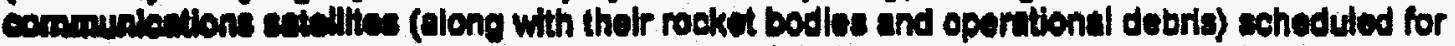
buseh duing the noxt exvaral years were not modeled. Exploslons were allowed to ocour at

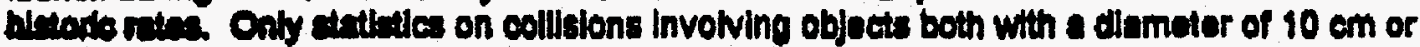

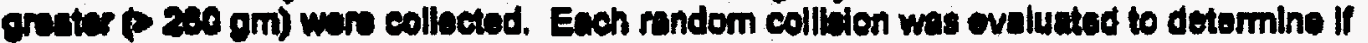
andilions exided for complete (eatastrophlc) frugmentation. statietics were complled for both entatropilo and nonmeatedrophic collisions.

Berith. A lotel of 684 collisions occurred duting the ton Monte Corio runs, representing an overage of 58.4 collasions per 100-year almulation. Floure 1 illustrates the cumulative number of ealliblans for each of the ten Morte Carto runs. The nen-linoer growth is indiontlve of the prowing sofellite population greater than $10 \mathrm{~cm}$ in diamoter. Table 1 summarizes the collision typus by dae (or maxs) ontegortes. For example, on avernge, two collalons accurred each run butwen objects in the 0.40-0.03 $\mathrm{m}$ and in the 3.08-8.31 $\mathrm{m}$ size bins (5.80-16.67 $\mathrm{kg}$ and 1071.3$2033.4 \mathrm{~kg}$ mase blns, respectively). The geomotric and arithmetic moans of total mess involved In the ealletons are Indleated buneath Table 1. The average combined mass of objecte involved la sll collitions was $2271 \mathrm{~kg}$ (oeometrio) or $2588 \mathrm{ko}$ (arthmelic).

Whing the ctandand NASA equation to determine the number of objecte greater than a olven mant

$$
\begin{aligned}
& \mathrm{CN}=0.4478\left(\mathrm{M} / \mathrm{M}_{\mathrm{O}}\right)^{+07400} \\
& \text { whare, } C N=\text { cumulative number of particles with maes } M \text { or larger } \\
& M_{k} \text { - mass of the smallest debris considered } \\
& M_{1}=\text { muse of the ejecte (1.0., total mase for antastrophlc collisions), }
\end{aligned}
$$

the mumber of debris dlameter $10 \mathrm{om}$ or greater is 403 (geometric) or 444 (arthmotic) (Flgure 2).

These numbers actually represent the most consorvative (least debris generoted) NABA earearment. In realty, the mass of oach object will be transformod into two separate, distinct dobits elouds with greater totel dobris than assuming s angle frogmentellon. Hence, if two objects, on $300 \mathrm{~kg}$ and one $1400 \mathrm{~kg}$, collided, two debrta clouds of 184 debrls and 281 debrts, mapecthvely, (total a 405) would be created Inetoad of a single debris cloud of 394 debris, es colculated with the equation ebove with a tolol mase of $2200 \mathrm{~kg}$. In addition, if a lowm mass caulvaliane of $148 \mathrm{gm}$ for $10 \mathrm{~cm}$ dlamoter dabris or if a combination of low intensthy cuplosiowcolltsion fragment generation (part of the mass is converted ubing low intenstly cquntions and poit of the mass is convorted using collislon equations) techniques are used, as is

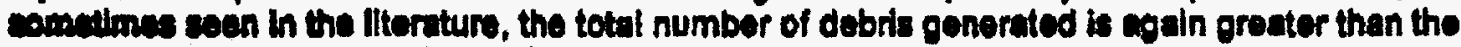
values elted above and in Floure 2.

Nicholes L. Johneon NABA Johnson Epuce Center 1 May 1987 
COLLISIONS BETWEEN OBJECTS GREATER THAN 10 CM DLAMETER (TEN 100-YEAR MONTE CARLO RUNS)

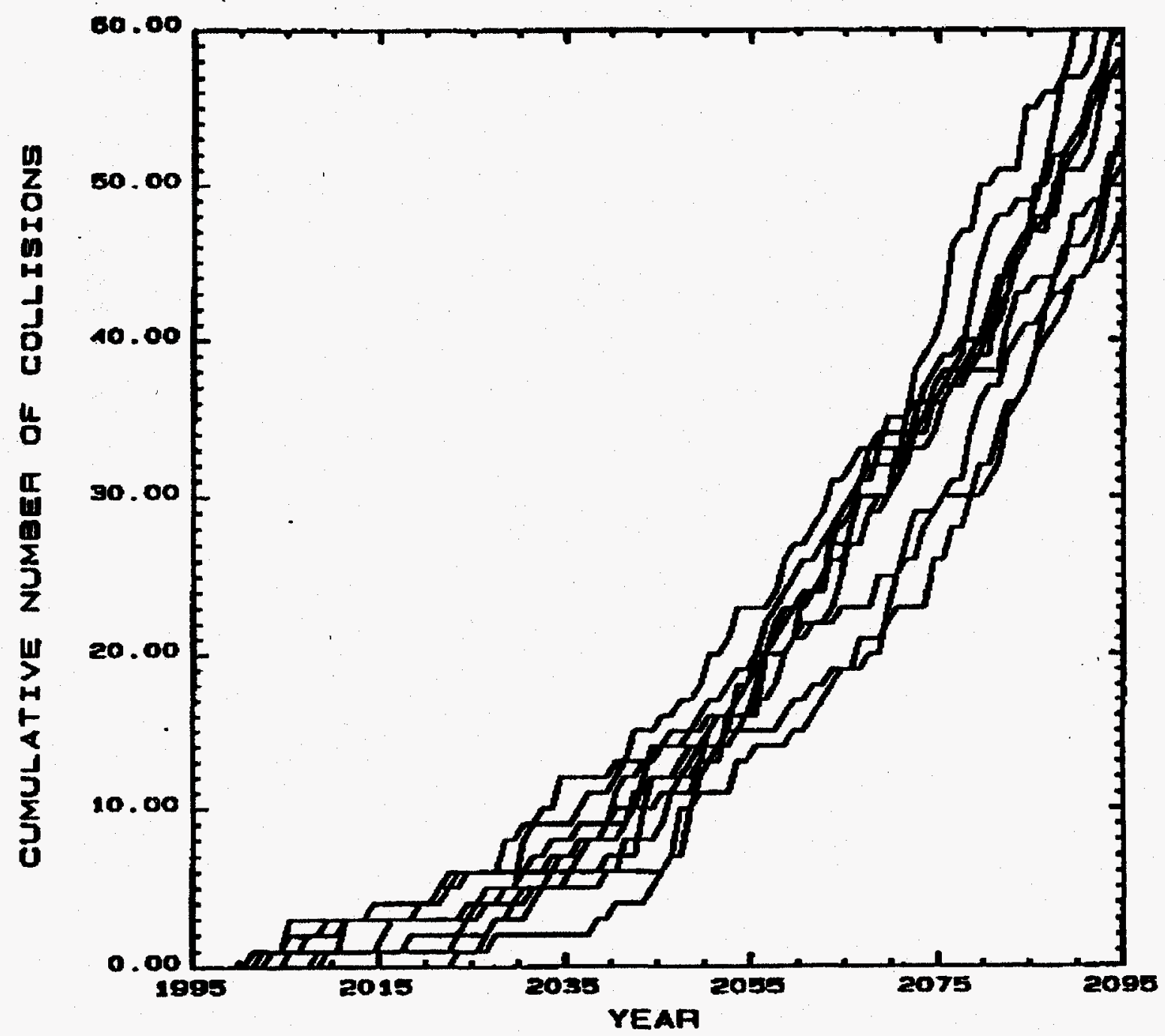


COLI.ISIONAL INTERACTION COHBINATIONS (EVOLVE 100 YEAR PROJACTION, BuSINESS AS OSUAL)

(10 MONTE CARLO ITERTTIONS)

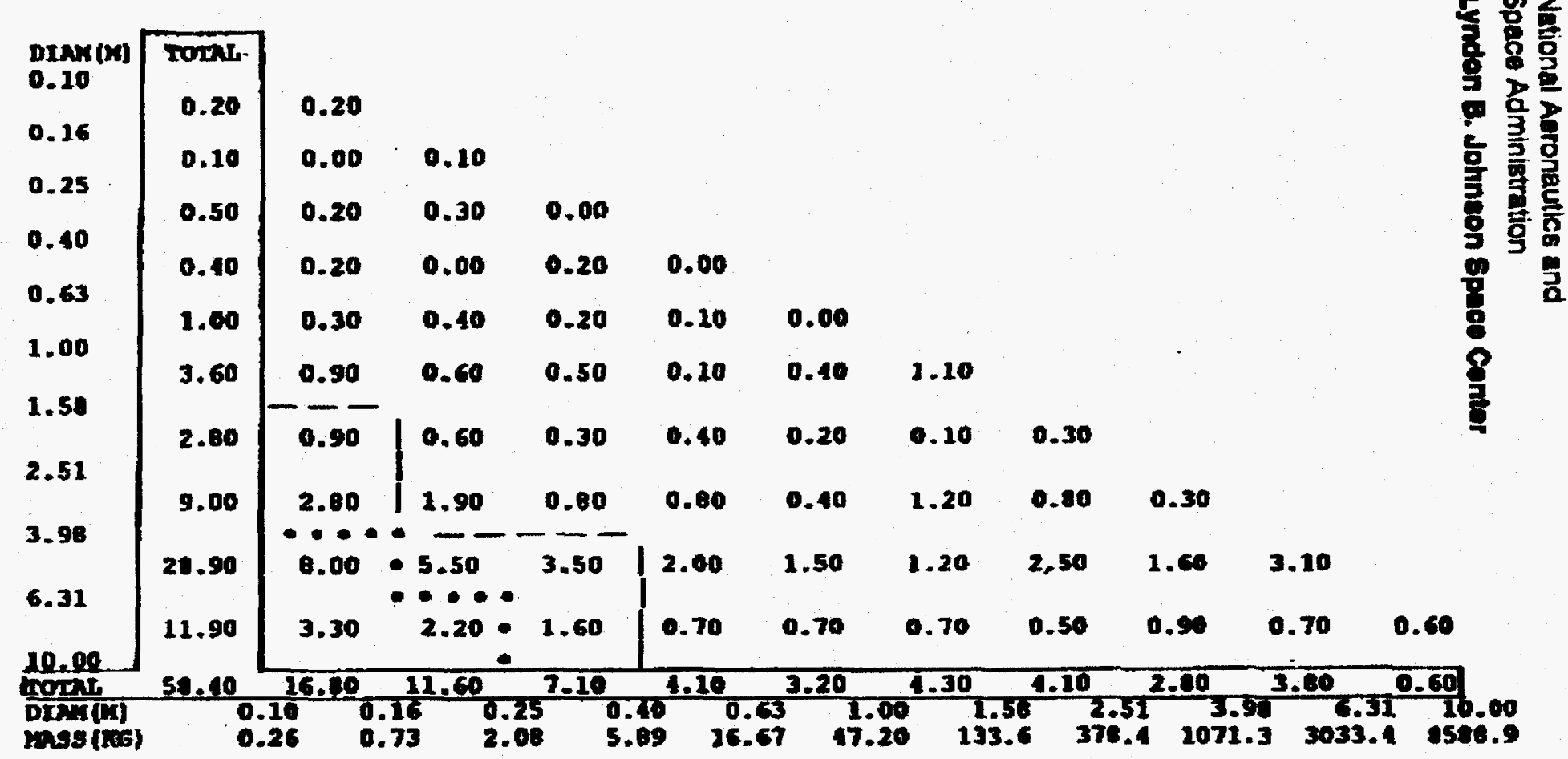

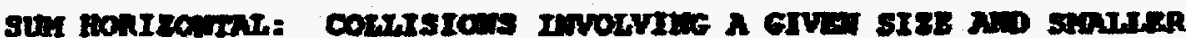

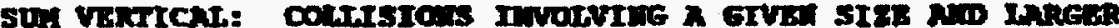

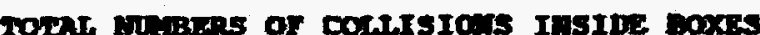

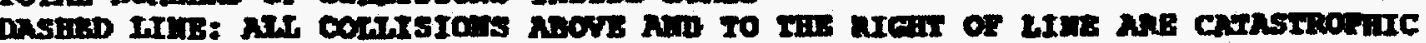

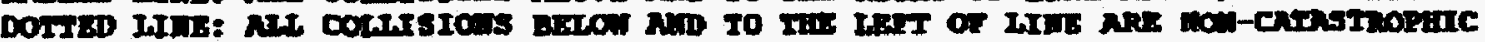

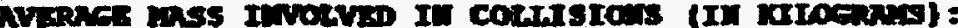

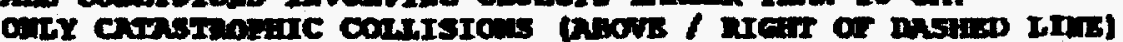

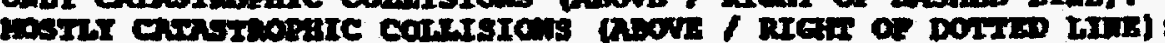
minas 2271 2007

Nurringtc
2506
2206
2372

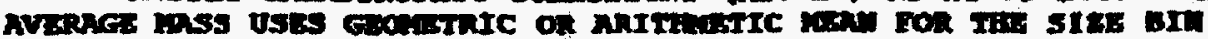

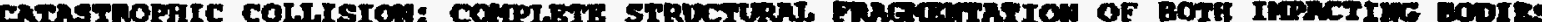




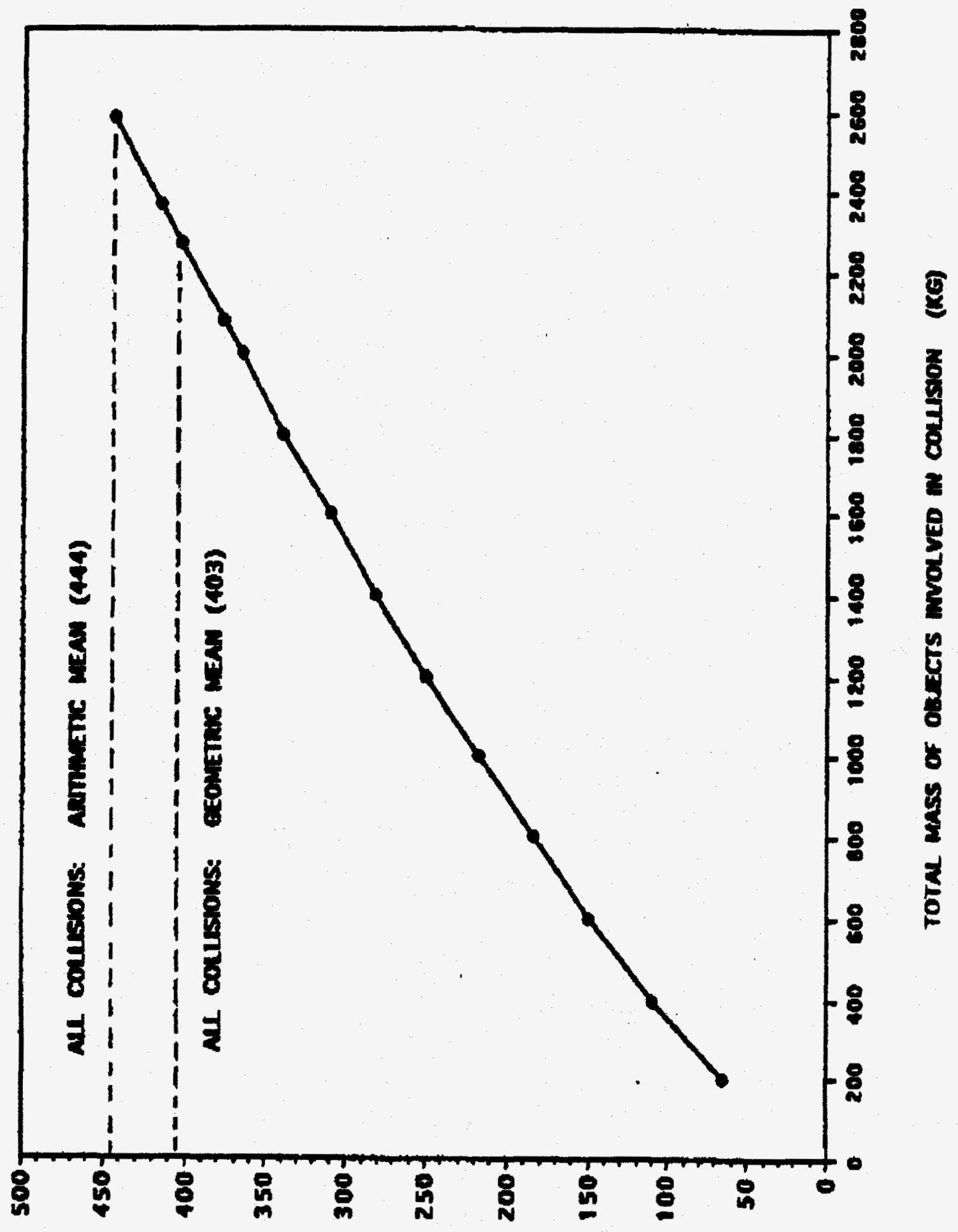

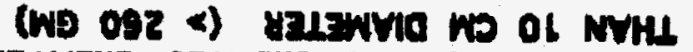

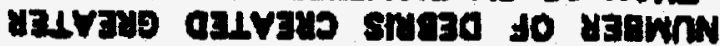

